\title{
Das Material der Pflicht.
}

Eine Studie über Fichtes spätere Sittenlehre.

Von Dr. Hans Freyer, Leipzig.

Der Gegenstand dieser Studie ist die Wandlung, die sich in der Philosophie Fichtes vollzogen hat, von der Sittenlehre und 2war von einem bestimmten Begriff der Sittenlehre aus gesehen.

$\mathrm{Ob}$ es möglich und zweckmäßig ist, gerade am Begriff des Materials der Pflicht die Entwicklung des Fichteschen Systems zn studieren, kann sich natürlich erst im Lanfe der Untersuchang zeigen. Aber eine vorläufige Rechtfertignng der Problemstellung kann durch den Hinweis gegeben werden, daB der Begriff Material der Pflicht (schreibt man ihn nur, wie Fichte ihn zuerst schreibt: Materiale der Pflicht, and fabt man inn nar so prinzipiell wie Fichte ihn faßt) das Korrelat zam Begriff des reinen Willens, also zum zentralsten Begriff der Sittenlehre ist. Kommt hinza, daB das Materiale in allem transzendentalen Philosophieren nicht nar zentraler Begriff sondern auch lebendigstes Problem za sein pflegt. Weil nämlich in der Transzendentalphilosophie der philosophische Wille auf die rationalen Formen des Bewabtseins gerichtet ist, ergibt sich ibr das Irrational-Materiale als Rest, als Grenzbegriff, als letztes und radikalstes Problem. Und von diesem Problem seinen Ausgang nebmen heißt die Rechnung des transzendental-philosophischen Systems von rückwärts nachrechnen oder, mit besserem Bilde, es von derjenigen Seite betrachten, auf der die spezifische Gerichtetheit seines Denkens naturgemäB alle Spannung der angelösten Probleme, also allen Antrieb zar Entwicklung anfhäufen mußte.

Die Verwandtschaft der Problemstellang mit Lask's Unternehmen, vom Irrationalen aus Fichtes Idealismus za begreifen; ist offenbar. Es gilt zunächst einfach Lask's Entwicklungsgeschichte der Fichteschen Erkenntnistheorie and Metaphysik durch eine 
solche seiner praktischen Philosophie zu ergänzen. Aber es wird hinzubehauptet, dab (aus Gründen die sich ergeben werden) das materiale Problem in der Ethik von noch fundamentalerer Bedeutang ist als in der übrigen Philosophie; sodaß die Wandlangen des Systems nicht nur, wie es bei Lask geschieht, aus ihm abgelesen, sondern zum gaten Teil ans ibm erklärt werden können.

Die Methode ist die begriffsgeschichtliche. Das heißt, daB das System als selbständige, vom Denker loslösbare geistige Realität angesehen werden soll, in dessen Inneren es Spannungen und Veränderungen, Leben und Entwicklung gibt. Das heißt aber nicht, daB philosophische Begriffe abseits von der geistigen Gesamtwirklichkeit, deren Teil and eine Ansicht sie sind, existierten. Sondern die These ist im Grunde, dab sich in Wandlungen der ethischen Begriffe Tieferes, nämlich eine Wandlung der Weltanschanang selbst ansspricht; daB sich also in einer Entwicklung des Begriffs Material der Pflicht eine Entwicklung der sittlichen Realität; za deren Formulierung der Begriff and das ganze System gebildet ist, vollzieht.

\section{Die Sittenlehre von 1798.}

Ich bezeichne mit dem Ausdrack "reiner Moralismus" diejenige seit Jahrhunderten lebendige und uns allen gegenwärtige Anschaung von dem sittlichen Handeln and seinem Wert, die von Kant zum Ausgangspunkt und zur Grundlage der Philosophie des Praktischen gemacht worden ist. Sie läßt sich so wenig wie irgend eine andere geistige Realität definieren, aber sie läbt sich leicht so beschreiben, daB jeder sie in sich findet. Sie sagt aus: daß unter den Motiven, die um den Willen werben, eines unverkennbar ausgezeichnet sei und allein die Züge einer höheren $\mathrm{Ab}$ kanft trage, die Pflicht. Jedesmal im Momente der Entscheidung sei der schlichte and bestimmte Raf der Pflicht hörbar. Es gebe da kein Deateln and kein Ausweichen: man könne ihm zawider handeln aber man könne ihn nicht überhören oder mißverstehen. Alles was diesem Rufe der Pflicht gemäb getan werde, sei eine sittliche Handlung, and es gebe kein sittliches Handeln außerdem. Es sei nun ganz gleichgültig, ob ich in großen oder in kleinen Verhältnissen meine Pflicht erfülle, wenn ich sie nur erfülle; aach was an Folgen ans meiner Tat erwachse, werde mir nicht zugerechnet. Denn weder die änßeren Umstände meines Lebens noch die Wirkangen meiner Handlangen in der kaasalen Welt seien von 
mir allein abhängig. So gewiß nicht in allen Lagen des Lebens für Glück und Erfolg, nur in wenigen für Ruhm and groBe Taten Raum sei: für den schlichten Heroismas des gaten Willens sei in allen Raum. Der bedürfe zu seiner Darstellang nicht irgend welcher Talente des Geistes, er bedürfe nicht einmal des Vermögens, seine Absichten durchzasetzen: er glänze wie ein Jawel, als etwas das seinen vollen Wert in sich selber hat. Diese Weltanschanung vollzieht eine unendlich kühne Umwertung aller Werte. Sie verwirft die geniale Tat, weil sie nicht aus Pflicht geschah, and verleiht dem geringfügigsten Tan einen unendlichen Wert am der Gesinnung willen ans der es hervorgeht.

Ich lasse zunächst die Frage beiseite, ob diese Ethik von allgemein menschlicher Geltung ist oder infolge einer geistesgeschichtlichen Entwicklung sich als die normale moralische Stimmung in den Gewissen Europas festgesetzt hat. Sie lebt jedenfalls in uns als eine Tatsache. Oder vielmehr: sie lebt in uns nicht in dem ruhigen kompalten Zustande der Tatsächlichkeit, sondern in der sublimeren Form der idealen Forderung. Sie lebt in uns, indem sie fordert in uns za leben. Sie macht uns immer wieder glaaben, dab sie unser besseres Teil sei, und dab sie leugnen einfach heiße: nicht die Kraft haben sie zu behaupten. Die freien Moralisten haben die Unsinnigkeit ihrer Umwertung bewiesen, sie haben sie als Vorwand des Egoismus oder als Moral des Sklavensinns diskreditiert, aber sie haben nicht die eigenartige Eindringlichkeit, mit der sie auftritt, gelengnet. Wenn das christianisierte Europa seine tiefste Frage stellen wollte, so hat es nicht die Frage nach dem Glück, nicht die nach dem vollkommenen Menschen, nicht die nach dem höchsten Gut, sondern es hat die Frage nach der Pflicht gestellt.

Kant hat also seine praktische Philosophie an den reinen Moralismus anknüpfen können, wie er die theoretische an die Tatsache der Wissenschaft anknüpfen konnte. Die Philosophie hat das Pflichtgebot so wenig zu begründen oder za beweisen, wie sie die Sätze der Mathematik za begründen oder za beweisen hat. Moral and Mathematik sind Fakta des BewuBtseins, sie gelten. Philosophie hat von ihnen auszagehen, sie bat die Bedingungen ihrer Möglichkeit zu suchen. Nun sieht Kant das Problematische im Gegebenheitscharakter der moralischen Tatsachen sehr klar; viel klarer als sein sorgloses Wirtschaften mit Beispielen vermaten läBt. Er weiB, daB es empirisch, durch Beispiele überhaupt nicht 
auszumachen ist, ob es einen kategorischen Imperativ gibt, and ob nicht alle, die kategorisch scheinen, doch rersteckter Weise hypothetische pragmatische Vorschriften sind ${ }^{1}$ ). Auf theoretischem Gebiete hatten ihm seine scharfsinnigsten Gegner eingewendet, $\mathrm{dab}$ er die apriorischen Formen, die sie nicht leugneten, nicht anfzudecken vermöchte. In der praktischen Philosophie macht er sich denselben Einwand selbst, aber er verschärft ihn. Nicht nar, daB für das reine Funktionsgesetz der praktischen Vernuuft, wenn es eines gibt, keine Quelle der Erkenntnis aufgezeigt werden kann. Der Philosophie des Praktischen fehlt überhaupt die Grundlage einer unzweifelbaren „Erfahrung ${ }^{4}$, die alles transzendentale Philosophieren braucht. Was die Erfahrung bietet: die empirisch bedingten Absichten, das ist moralisch bereits zweideutig, und das moralisch Eindentige: die reine Form des Willens, ist unerfabrbar. Puritanische Traditionen: Wir wissen nicht ob wir verworfen oder auserwählt sind ${ }^{2}$ ). Man weiß, daß Kant auf der nächsten Seite. vom Sittengesetz als einem Faktum der Vernunft spricht, das sich uns schlechterdings anfdringe, and aller Orten an das Urteil der gemeinsten sittlichen Erfahrung appelliert. Solche Discrepanzen gründen in dem andeutangsweise beschriebenen, komplizierten Charakter, mit dem das System des reinen Moralismus im Erlebnis auftritt. Es ist mehr aufgegeben als gegeben: moralistisch denken ist selbst eine moralische Forderang. Aber diese Schwierigkeit anerkannt und hingenommen, hat die Philosophie dem reinen Moralismus gegenüber dieselbe Aufgabe wie der Mathematik gegenüber. Sie hat von den Erlebnistatsachen, die man sieht, zu den notwendigen Funktionsgesetzen der. Vernunft zurückzugehen, die man nicht sieht. Wodurch der reine Moralismns aus einem System des anmittelbaren, gemeinen Urteils eine Philosophie des Praktischen würde.

Was hat nun Kant in dieser Rücksicht geleistet? Sieht man von der rein analytischen Leistung, daB er die Formeln für den kategorischen Imperativ findet, ab, so bringt Kant einen großen konstruktiven Gedanken bei. Solange man den Menschen, so überlegt er, durch die Pflicht an irgend ein fremdes Gesetz gebunden denkt, maB ein Interesse als Reiz oder Zwang, sich dem Gesetz za unterwerfen, ins Spiel geführt werden, und alle Arbeit, einen

1) Grandlegung zur Metaph. der Sitten S. 53 u. anderswo.

2) S. Scheler, Der Formalismus in der Ethik u. die materiale Wertethik. 
obersten Grund der Pflicht zu finden, ist verloren. Vielmehr : das Sittengesetz muß das Gesetz meines Willens selbst, die Selbstgesetzgebung der praktischen Vernunft sein. Das ist der große konstruktive Gedanke Kants: Sittlichkeit ist Autonomie, weiter nichts. Es ist in mir ein reiner Wille. Er ragt ans der intellegiblen Ordnung der Dinge in mich herein and konstituiert mich als freies, vernünftiges Wesen. Er ist „frei im positiven Verstande ${ }^{\alpha}$ d.h. er ist autonom, er gibt sich selbst sein Gesetz. Wäre ich nur mein reiner Wille und nicht zugleich sinnliches Wesen, so würden alle meine Handlungen der Autonomie des Willens gemäß sein. So aber hat er sich mit meinen sinnlichen Neigungen heramzaschlagen: in der gaten Tat bricht er durch sie durch wie die Sonne durch die Wolken. Er erlebt aber in diesem Kampf eine Veränderung. Er wird aus dem selbstverständlichen, gleichsam genialen Wollen seiner selbst zam harten kategorischen Gebot, er erscheint als Sollen. Das Sollen ist das Sich-selber-Wollen des Absoluten in mir, sofern ich sinnliches Wesen bin. Durch diesen Dualismus ist der synthetisch-praktische Satz des kategorischen Imperativs konstraktiv abgeleitet; nungefähr so wie za den Anschaungen der Sinnenwelt Begriffe des Verstandes, die für sich selbst nichts als gesetzliche Form bedeaten, hinzukommen and dadarch synthetische Sätze a priori, auf welchen alle Erkenntnis einer Natur berulat, möglich machen". Der ganze Gedanke, daB die allgemeingültigen Beziehungen der Wirklichkeit aus einer ursprünglichen formenden Kraft des Geistes stammen, geht ja von vorn herein weit über die bloße Anfweisung des a priori hinaus. Er ist das konstraktive Moment in Kants Philosophie and leitet seinen Transzendentalismus beinahe in eine Metaphysik des spontanen Geistes hinüber. Hier in der praktischen Philosophie tritt dieser Gedanke am klarsten und schönsten heraus. Denn es handelt sich hier nur am eine apriorische Form, die za erklären ist. Die Spontaneität aber, durch die sie konstraiert wird, ist gleichsam das Innerste unseres Innern, das Absoluteste des Absoluten in unserer Vernunft.

Der Kritiker der Erkenntnis ist schon beinahe za weit gegangen und beeilt sich das Resaltat mit Kautelen $z a$ versehen. Nor unter Voraussetzang eines freien Willens und seiner Autonomie ist ein kategorischer Imperativ möglich. Aber wie diese Voraussetzang selbst möglich ist, wie das Fanktionieren des autonomen Willens za denken ist, $n$ wie reine Vernunft praktisch sein 
könne ${ }^{u}$, das zu erklären ist alle menschliche Vernunft gänzlich unvermögend. Denn nusere Erkenntnis tastet sich von Bedingung za Bedingang, aber hier ist ein anbedingtes praktisches Gesetz za begreifen. Die Unbegreiflichkeit des moralischen Imperativs zu begreifen ist das Letzte, was von der Philosophie gefordert werden kann. -

Soweit kommt Kant in der philosophischen Konstruktion des reinen Moralismus. Er konstruiert die Absolntheit des Sittengesetzes and den Charakter des Sollens, mit dem es im Bewaßtsein auftritt. Aber die Konstruktion läBt sich viel weiter treiben. Fichte setzt hier Kants Arbeit ganz kontinuierlich fort. Er nimmt sehr früh den Kantischen Grundgedanken anf, daß sich im empirischen Ich das Absolute za verwirklichen strebe, and $\mathrm{daB}$ der Ausdruck dieses Strebens das Pflichtgebot sei $^{1}$ ). Die Wissenschaftslehre von 1794 fühlt sich bereits Kantischer, als Kant seiner kriticistischen Terminologie zu reden erlaubt habe. Wird es irgendwo klar, so merkt sie an, daB Kant seinem kritischen Verfahren, nar stillschweigend, gerade die Prämissen der Wissenschaftslehre zugrande gelegt hat, so ist es hier in der Frage des kategorischen Imperativs. Wie hätte er jemals auf einen kategorischen Imperativ, als absolutes Postulat der Übereinstimmang mit dem reinen Ich kommen können ohne aus der Voranssetzung eines absoluten Seins des Ich? Aber mit der Idee des reinen Ich und seiner notwendigen Tathandlungen, also mit der Wissenschaftslehre, ist der reine Moralismus da: er ist ${ }_{n}$ mit dem System des transzendentalen Idealismus unzertrennlich verknüpft ${ }^{42}$ ). So will die Sittenlehre von 1798 nichts als die vollständige philos ophische Konstruktion des reinen Moralismas sein, and der reine Moralismus kann nicht zielbewußter konstruiert werden als er 1798 konstruiert worden ist. Wir denken diese Konstruktion nach, am den Begriff "Material der Pflicht" and seinen Ort im System za finden.

$\mathrm{Da}$ ist ein Faktam des Bewaßtseins. Ich finde in mir einen Willen, der sich unabhängig von allen Einflüssen der Sinnenwelt rein durch sich selbst bestimmen kann: ein Freies in des Worts verwegenster Bedeutang, fähig unverursacht eine Reihe von Ursachen

1) Siehe: VI, 59 (Beiträge zur Berichtigung usw.). I, 22 (Recension des Aenesidem). I, $247 \mathrm{ff}$. (W.-L. ron 1794).

2) $\nabla, 887$ (Rückerinnerungen usw.). 
von vorn anzufangen, ein unbewegter Beweger. Meine Philosophie, als transzendentale, macht sonst vor sogenannten Tatsachen nicht Halt. Dafür ist sie Philosophie, daß sie die Tatsachen überwindet, als Principiate aus Prinzipien ableitet. Es fällt ihr nicht ein, die Dinge in Raum and Zeit, so harte Tatsachen sie sein mögen, anbesehen hinzanehmen: sie deduziert den Raum, die Zeit, and die Dinge daza, mitsamt ihrer Faktizität. Die Popalarphilosophie pflegte sich auf Tatsachen zu berufen, wenn sie nicht weiter kam: die Transcendentalphilosophie kommt immer weiter wenn sie will. Der springende Pankt ist: hier will sie nicht weiterkommen. Kein theoretischer Vernunftgrand, ein praktisches Interesse, ein freier EntschluB setzt dem sonst ungezähmten Fluge des Raisonnements seine Grenzen. Ich würde mich selbst, als selbständiges Wesen, vernichten, wenn ich meine absolute Freiheit aus irgend einer Notwendigkeit herleitete. Niemand hindert mich, mich za vernichten: aber ich will mich nicht vernichten, daram halte ich diese eine Tatsache für das absolut Positive und Kategorische, für meine letzte Bestimmung. Mit Fichtes Formeln: Ich will selbständig sein, daram halte ich mich dafuir. Hier ist etwas was den Geist bindet, weil es das Herz bindet. Es ist kein Wissen, es ist ein EntschluB das Wissen gelten zu lassen. Man macht in diesem Systeme sich selbst zam Boden seiner Philosophie, darum kommt sie demjenigen als bodenlos vor, der dies nicht vermag. Was für eine Philosophie man wähle, hängt davon ab, was für ein Mensch man ist ${ }^{1}$ ).

"Ich bin wirklich frei“ ist also der erste Glanbensartikel, von dem die Philosophie anzufangen hat. Wie ist aber dieses Absolute im Wollen za denken? Ein Ringen mit dem Wort beginnt, nar dem der Mystiker vergleichbar, wenn sie ihr Absolntes, den Moment der Vereinigang mit Gott, in ihre Rede zwingen ${ }^{2}$ ). Es soll nicht etwa das wirkliche Wollen gedacht werden, denn in ihm wird irgend etwas gewollt: dann aber habe ich mich nicht, wie ich an and für mich bin, sondern wie ich in einer gewissen Beziehnng anf anBer mir befindliche Dinge werden kann. Nar indem ich alles Objekt wegdenke, kann ich das reine Sein meines Willens and so mein wahres Wesen finden. Das Bild der Stahl-

1) IV, 54 u. 25 f. (System der Sittenlehre), II, 253 (Bestimmung des Menschen), I, 434 (Erste Einleitung), V, 181 ff. (Grund unsres Glaubens).

2) IV, 28 (Sittenlehre). 
feder, die auch wenn kein Drack von außen auf sie ausgeübt wird, ihre eigene Elastizität als innere wesentliche Tendenz in sich hat, kann der hilfslosen Phantasie als Ausgangspunkt gegeben werden. Und um nur überhaupt einen Namen für das Unnennbare zu haben, sei der reine Wille als Tendenz sich selbst absolut zu bestimmen, als absolute Unbestimmbarkeit durch irgend etwas außer ihm, als Tendenz zur Selbständigkeit um der Selbständigkeit willen beschrieben. Aber diese Beschreibung denkt das Ich lediglich als Objekt, sie sieht nicht, daB es zugleich seiner selbst bewaßt, Intelligenz ist. Das aber ist kein nnwesentliches Accidenz jener Tendenz zur Selbständigkeit, sondern ihr höchst wesentlich: nur eine Intelligenz kann frei sein. Denn näher zugesehen: die Elastizität der Stahlfeder ist bestimmt durch ihre Natur, diese durch ein anderes Sein; es geht eine stetige Reihe von einem Sein zam andern. Also weg von dem Bilde, das nichts helfen kann, zar entschlossenen Anschauung unseres inneren Wesens. Hier findet wirklich ein Sich-selbst-Bestimmen statt. Das Ich kann sich selbst bestimmen, weil es Intelligenz ist: sein Denken wird Grund seines Tuns. Die Tendenz zur Selbsttätigkeit ist nur dadurch wahre Freiheit, daß sie zugleich wesentlich intelligent ist; nar dadarch wird sie unter etwas gebracht, das höher ist als alles Sein : anter den Begriff.

Und was wird nun ans jener absoluten Tendenz zur Selbsttätigkeit, dadarch daß sie unter die BotmäBigkeit der Intelligenz kommt? Das intelligente Ich findet seine Selbständigkeit nicht als bloßes leeres Vermögen, das es gebrauchen könnte oder auch nicht, sondern als sein notwendiges Wesen, als seine Urbestimmung, durch die es erst. Vernunftwesen wird. Es setzt seine Selbständigkeit also als wesentlich, als notwendig. Versteht sich: nicht als notwendig nach Naturgesetzen, da es ja eben frei ist, sondern als notwendig im Sinne einer Norm. Die Tendenz zar Selbständigkeit, in die Intelligenz aufgenommen, wird notwendig za der Norm, sich durchans nach dem Prinzip der Selbständigkeit $z$ a bestimmen. Das ist die absolate Synthese von Freiheit und Gesetz: die Freiheit unter dem Gesetz frei za sein. Eine Freiheit aber unter einem Gesetz, das ergibt das Phänomen der Pflicht. Denn die freie Handlung kann nie mechanisch notwendig; sie kann nur dem Begriffe nach notwendig sein; Freibeit maB nie, sie soll. Wir sehen: Fichtes Deduktion ist am Ziele. Sie hat das Prinzip der Sittlichkeit erreicht. Es entsteht ans dem 
Zusammenwirken der wesentlichen Vernunftfunktionen. Seine Form ist kategorischer Imperativ, sein Gehalt lautere Antonomie; nicht nur daB in ihm nichts gefordert wird als absolute Selbständigkeit: sondern der ganze Begriff der notwendigen Unterwerfung unter ein Gesetz entsteht dem Ich lediglich dadurch, daß seine Intelligenz auf sein wahres Wesen, auf seine Selbständigkeit reflektiert. Es macht sich sein eigenes Wesen zum eigenen Gesetz.

Wie also Vernunft praktisch sein könne, so kann Fichte mit einer Geste gegen Kant seine Deduktion beenden ${ }^{1}$ ), läBt sich klar einsehen. Praktische Vernunft ist gar nicht das wunderbare und unbegreifliche Ding, für welches sie zuweilen angesehen wird, ist gar nicht etwa eine Vernunft anßer der theoretischen. Aus dem System der Vernunft ïberhaupt ist der kategorische Imperativ der Antonomie abgeleitet. -

Wie das Resultat zeigt, deckt sich das System der Sittenlehre bis hierher mit der Kritik der praktischen Vernunft. Es philosophiert intensiver als diese, aber es geht nicht über ihren Problemkreis hinaus. Aber das neue, für Fichte originale Problem ist doch ron Anfang an vorbereitet. Denn von Anfang an ist gesagt, daB es in der Wirklichkeit nur ein Wollen in Bezug anf einen Gegenstand, nur ein Etwas-Wollen gibt; und daß die bisher aufgestellten Sätze, indem sie die Gesetzmäßigkeit des reinen Willens suchten, aus dem konkreten Akt die bloße willentliche Form herausgelöst haben. Die Transcendentalphilosophie muß so verfahren, denn jedes Apriori ist, formallogisch betrachtet, ein abstralrt Allgemeines, eine Form; aber sie maß sich dieses Charakters ihrer Gegenstände bewaßt sein und zuletzt, irgendwie, den Weg zur konkreten Wirklichkeit zarückfinden. DaB auf dem Gebiete der theoretischen Vernunft die kategorialen Formen jederzeit an ein Material gebanden sind, hat Kant immer aufs nachdrücklichste betont: sein Begriff der Erfahrang, sein Kampf gegen die Metaphysik beruht darauf. Anf moralphilosophischem Gebiete hat erst Fichte mit dieser Erkenntnis ernst gemacht.

Wie nan die Konstraktion des theoretischen Geistes, wenn sie aus dem System der reinen Formen ins Materiale der Erkenntnis vordrang, auf das Ding an sich stie $B$, diesen Problemknäuel, den gerade damals viele aufzulösen, einige zu durchhauen an der Arbeit waren, so bedentet Fichtes Fortführang der Kantischen De-

1) IV, 57 (S.L.). 
duktion der Maral das theoretische Wagnis, das Materiale der Sittlichkeit in die gedankliche Konstraktion aufzunehmen. Für den reinen Moralismus als vorphilosophisches System der Lebensführung bietet das in Rede stehende Problem keine Schwierigkeit, or kennt es kaum. Sein Satz von der Sittlichkeit als einem Tan ans Pflicht ist eine onschädliche Abstraktion ans lauter vollgültigen Erlebnissen and läBt dem individuellen sittlicben Akt die Dignität einer konkreten Wirklichkeit, die ihren Wertcharakter selbstverständlich mit sich führt. Die philosophische Konstraktion aber hat die reine willentliche Form der sittlichen Handlung, indem sie sie als Streben nach Selbständigkeit um der Selbständigkeit willen oder irgendwie sonst deduktiv bestimmte, verselbständigt and (recht verstanden) verinhaltlicht. Sie mab nun fragen: welche Realität das Streben nach Selbständigkeit in der konkreten Handlung habe and welches seine Beziehnngen zu deren materialer Bestimmtheit sei. Sie steht also vor einem viel schwerer wiegenden and eigentlich überhaupt erst vor einem Probleme des Materialen der Pflicht. Die Beziehnng von Form und Inhalt, die sich nach der ganzen Anlage der Deduktion als vorlänfige Formulierang für das Verhältnis des reinen Willens zur konkreten Handlang darbietet, verschleiert auf die Dauer die Problematik dieses Verhältnisses and leistet zadem keine Weiterfübrung der Deduktion, wie sie die Methode der Wissenschafts]ehre fordert. Höchst kompliziert gebaute Partien des Systems der Sittenlehre nnternehmen die Lösung des Problems, indem sie Gedankengänge, die im Ganzen der Wissenschaftslehre sehr verschiedenen Höhenlagen angehören, zusammenarbeiten, um schlieBlich den Gedanken des Materials der Pflicht in eine einheitliche Formel zu zwingen. Unsere Analyse hat zunächst diese Gedankengänge in drei übereinander liegenden Massen zu ordnen, von denen jede die tieferliegende in systematischer Hinsicht „aufhebt ${ }^{\text {. }}$.

Der Gedankengang der ersten Ebene greift, das Endergebnis der bisherigen Dedultion zunächst auBer Acht lassend, auf den schlichten Inhalt des tatsächlichen Erlebnisses zarück und interpretiert: Ich soll etwas, d. h. ich soll etwas außer mir hervorbringen ${ }^{1}$. Non aber kann ich das, was von mir gefordert wird, nicht ans dem Nichts hervorbringen; ich muB einen Stoff meiner Tätigkeit haben. Dieser Stoff, das ergibt sich schon hier, maB

1) IV, 66 (S.-L.). 
modifizierbar sein, sonst könnte ich nicht anf ihn tätig sein, aber er muß seine eigentümliche, unaufhebbare, meinen Willen zwingende Gesetzlichkeit haben, sonst wäre er kein Widerstand, und meine Tätigkeit wäre in jedem Moment vollendet ${ }^{1}$ ). Er ist die Welt als ein mannigfaltiges in Ranm und Zeit mit ihren Bestimmangen, die nun gerade so sind, wie sie sind; and die meinen Willen, nicht als freien Entschln $B$ natürlich, aber als wirkliches Wollen mitbestimmen, indem sie ihm ein inhaltliches Ziel geben and die Reihe der Mittel anweigerlich vorschreiben, die er zar Erreichung des Ziels zu durchlanfen hat. Nach seiner prinzipiellen Fanktion für die philosophische Erfassung des konkreten sittlichen Aktes betrachtet, erklärt dieser Widerstand die Realisierung des reinen Willens, sein Eingehen in die Zeit. Denn dieser ist ohne ihn schlechthin einer, reine Identität, losgelöst von Zeit and Mannigfaltigkeit ${ }^{2}$ ); formallogisch charakterisiert: ein abstrakter Begriff; metaphysisch substituiert: unsere Existenz in der intelligiblen Welt. Erst durch das Objekt, auf das ich wirke, durch den Widerstand, den ich füble and überwinde, wird meine Tätigkeit in die Zeit auseinandergelegt zum empfindbaren Faktam, zur wirklichen Tat (die meine Existenz in der Sinnenwelt ist) ${ }^{3}$ ). Resultat dieses ersten Gedankenganges: was wir in unserer Wirksamkeit wahrnehmen, ist die Synthesis unsrer reinen identischen Tätigkeit mit dem Mannigfaltigen eines Widerstandes.

Nan aber wird die oben angedentete Problematik des Verhältnisses zwischen den beiden in der Synthesis vereinigten Elementen aktuell and treibt den Gedankengang in eine höhere Schicht hinauf. Eine Begriffsbildung, mit der Fichte arbeitet, seit er za philosophieren angefangen hat (das System Spinozas, dem er in der Jugend anhing, legte sie ihm nahe), der gedankliche Zusammenhang der Wissenschaftslehre von 1794 and vor allem die inhaltliche Bestimmung des reinen Willens als eines absolnten Triebes nach Selbständigkeit führen vereint za der Lösung, die nun erfolgt. Sie lautet: der reine Wille macht das eigentliche innere Wesen des Ich allein aus; er wird zur konkreten individuellen Realität dadarch, dab die materialen Bestimmtheiten, die durchaus nichtig sind, ihn einschränken. Das Reale ist eingeschränktes

1) IV, 81 f. (S.-L.).

2) IV, 66 (Sittenlehre).

3) IV, $96 \mathrm{f}$. (Sittenlehre). 
Ideales. Formelhaft: „Das was der Mensch ist (sc. der empirische, reale Mensch) ist er nicht darum weil er ist, sondern daram weil etwas a uber ihm ist " ${ }^{1}$ ); "durch die verschiedene Handlangs art der Natur werden die Individuen und das was man ihre besondere individuelle Natur nennt bestimmt" ${ }^{2}$ ). Es gibt keine apriorischen Gesetze dieser Beschränkang: hier ist die Sphäre der reinen Faktizität, des transcendentalen Zufalls, des absolut irrationalen Individuationsaktes, den die Wissenschaftslehre von 1794 formuliert ${ }^{3}$ ). Er erzeugt ein aus anserem inneren freien Wesen unableitbares System unserer Begrenztheit, ein ursprüngliches bestimmtes System von Trieben and Gefühlen ${ }^{4}$ ), das die Natarseite des Doppelwesens, das wir sind, ausmacht. Mit vollkommener Konsequenz werden aus dieser Naturhaftigkeit der individuellen Charaktere alle Folgerungen gezogen. „Unsre ganze sowohl innere als äußere Welt, inwiefern das erstere nar wirklich Welt ist, ist auf alle Ewigkeit hinaus prästabiliert ${ }^{45}$ ). Und mehr: als Natnrerscheinung müssen wir in die übrige Natar hineingestellt und naus dem ganzen System der Natur abgeleitet" werden. Das geschieht durch eine dynamistische Naturphilosophie ${ }^{6}$, nach welcher die Natur ein geschlossener Umkreis der Wechselwirkang, ein organisches Ganzes von einander beschränkenden Teilen ist, in deren jedem die Tendenz nach Realität, die über das ganze ausgegossen ist, lebendig ist. Weil nun jeder nar Teil ist, geht ihm alle Realität der übrigen Teile ab, und es bleibt ihm für diese nur Trieb. Alles ist also in der Qualität seines Naturtriebes durch alles mitgebildet. Der Mensch ist in dieser Natur, der es notwendig ist sich in reelle Ganze zu organisieren, ein organisiertes Natnrprodakt anter anderen and bezieht, wie Pflanze and Tier, alle Gegenstände der Natar auf seinen natürlichen Trieb der Selbsterhaltang. Das ist ein vollkommen geschlossener Kreis, der das empirische Ich ans einem Gesetz der physischen Notwendigkeit erklärt. Nur der reine Wille ragt in dieses System, ans dem er nicht erklärt and das nicht aus ihm erklärt werden kann, hinein,

1) VI, 296 (Bestimmung des Gelehrten 1794).

2) ebda.

8) I, 279.

4) IV, 109 (Sittenlehre).

5) IV, $101 \quad n$

6) IV, 110 ff. $\quad$ n 
durch die unerklärliche Beziehnng mit ihm verbunden, das es ihn zam Realen, Konkreten, Materialbestimmten einschränkt.

Es ist bekannt, daB der radikale Idealismus der Wissenschaftslehre den Gedankengang noch einmal in eine höhere Ebene za führen vermag, indem er das einschränkende Materiale als NichtIch, also als transcendental-sekundär und $v 0 \mathrm{~m}$ Ich gesetzt, begreift; welche Deduktion natürlich nur das Daß des Materialen, nicht das Wie seiner Qualitäten erreichen kann. Denn daß die Produktion des Nicht-Ich durch das Ich durchaus nicht die Ableitbarkeit der materialen Bestimmungen ans den formal-apriorischen mit sich führt, sondern eine „projectio per hiatum irrationalem ${ }^{*}$ ist, diese spezifisch Fichtesche Erkenntnis wird, nachdem die vorübergehenden Neigungen der Wissenschaftslehre von 1794 zar metaphysischen Substitution des absoluten Total-Ich and zam Emanatismus überwanden worden sind, von Fichte während der ganzen ersten Periode seines Denkens festgehalten. Das Apriori ist blob formal and das Individaell-Materiale ist schlechthin irrational and faktisch. So gibt es rom Nicht-Ich als so und so bestimmtem keine Deduktion und, da genetische Deduktion die Methode der Philosophie ist, keine philosophische Erkenntnis. Es gibt auf das Nicht-Ich nur die übertheoretische, sittliche Beziehung: daB das Ich es setzt, am praktisch sein zu können. Kein Grund läßt sich für das Einzelne der Welt angeben, nur ein Sinn. Es ist die durch das theoretische Ich in ränmlich-zeitliche Realität verwandelte, selbstgesetzte und unbegreifliche Beschränkang des praktischen Ich; also die fortwährende Deutang des Pflicht-Gebots; der lebendige Ausdruck dessen, was da sollst da da ja sollst; das versinnlichte Materiale unserer Pflicht. „Unsere Pflicht ist das intellegible An-sich, welches durch die Gesetze der sinnlichen Vorstellung sich in eine Sinnenwelt verwandelt" "). Wiederum muß die sogenannte Innenwelt ("sofern sie nur wirklich Welt ist"), also unser ganzer individueller Charakter in die sinnliche Welt eingerechnet werden. Nur indem ich mich darch die Gesetze der sinnlichen Anschanung und des diskarsiven Denkens als $O b j e k t$ erblicke, erblicke ich den reinen Willen, der mein Wesen konstituiert, als Naturtrieb und die nnerklärliche Wechselwirkung der beiden Triebe in mir ist „die Wechselwirkung eines und desselben Triebes mit sich selbst ${ }^{42}$ ). Der Kreis ist geschlossen,

1) IV, 172 (S.-L.).

2) IV, 130. 
das Materiale der Pflicht hat seinen Ort im System der reinen Sittenlehre. Es ist Resultat einer generell deduzierbaren, qualitativ unbegreiflichen Selbstbeschränkung des reinen Willens.

Der ganze dreistufige Gedankengang läßt zwei Probleme zurück. Denn wenn anch durch die konsequente Einrechnung des Empirisch-Seelischen in die natiurliche Welt die individuellen Charaktere und ihre natürlichen Systeme der Triebe and Neigungen als blobe Materialisierung des reinen Ich erkannt worden sind, so bleibt doch die Frage bestehen: wie denn der reine Wille, den die schlichte Erfahrung in jedem sittlichen Akt wahrnahm, in diese Welt seines sinnlichen Erscheinens direkt eingreifen könne, and welches überhaupt seine Beziehang za dieser seiner Naturansicht sei. In der Tat, so lautet die Antwort, diese Beziehung ist ausschlieblich and ihrem Wie nach unbegreiflich in der Doppelnatur des Menschen hergestellt. Der Mensch kann sich als Objekt, kann sich aber auch als Subjekt erblicken; and reiht sich im ersten Falle in die Natur, im zweiten in eine intelligible Welt ein. Von dem Naturtrieb und dem kausal geschlossenen System, in dem er drin steht, ans betrachtet ist der reine Trieb eine absolut neue Kraft, die alle Kansalität überfliegt, ein Sichlosreißen von aller Natur durch Freiheit. Sein Durchbruch erfolgt, weil er erfolgt; er soll erfolgen (weil das empirische Ich dem reinen entsprechen soll), aber er maB nicht erfolgen ${ }^{1}$ ). So klar beide Triebe im sittlichen Erlebnis von einander geschieden sind (der eine änßert sich als Sehnen, der andere als absolute Forderang; die Befriedigung des einen als Lust, die des andern als kalte Billigung ${ }^{2}$ ) - so unbegreiflich ist die Tatsache ihrer Wechselwirkang, so unlösbar das Problem ${ }_{n}$ der Freiheit in Anwendung auf das empirische Subjekt": "Einen Akt der Freiheit begreifen zu wollen ist absolut widersprechend " ${ }^{3}$ ).

Dies das erste Problem. Das zweite ergibt sich, sobald wir uns wieder auf die Bedeutung des reinen Willens als Triebes nach Selbständigkeit um der Selbständigkeit willen besinnen. Soll dieser Trieb Kansalität haben, so läßt sich das zunächst nor so denken, daB er sich andanernd von allem Naturtrieb befreit, daB also aus ibm lediglich Unterlassungen, nie positive Handlungen

1) IV, 179 (Sittenlehre).

2) IV, $145 \mathrm{ff}$.

3) IV, 181 
(außer der inneren Handlung der Selbstbestimmung) erfolgen können. Wir kämen also auf eine gänzliche Vernichtong alles Handelns, „wie die Mystiker, nach denen wir uns in Gott verlieren sollen ${ }^{\prime \prime}$ ). Dasselbe in prinzipiellster Formulierang ${ }^{2}$ ): Alles wirkliche Handeln ist empirisch and der sinnlichen Sphäre eingeordnet; ein reiner Wille ist kein wirkliches Wollen, sondern eine bloße Idee. Wie kann er trotzdem Realität haben? Nach den Gesetzen der Synthesis so: daß die sittlichen Handlangen in ein er Reihe liegen, durch deren Fortsetzung dàs Ich unabhängig werden müBte. "Ich soll frei handeln, damit ich frei werde". Im Sinne dieser Annäherung an die absolnte Selbständigkeit hat das Sittengesetz, auf den empirischen Menschen bezogen, einen bestimmten Anfangspunkt: die bestimmte Beschränkung, in der sich das Individunm findet; es hat ein bestimmtes nie zu erreichendes Ziel: absolute Befreiung von aller Beschränkang; es fordert von jedem Menschen in jeder Lage etwas Bestimmtes als pflichtmäBig: den Fortschritt anf der durch die beiden Punkte bestimmten Reihe. Die unmittelbare and unbestechliche Stimme des Gewissens verkündet in jedem Moment dieses hic et nunc Sittliche, das die transcendentale Moralphilosophie als ihren letzten Begriff synthetisch findet.

Der Irrtum der Mystiker besteht also, an Fichtes Sittenlehre gemessen, nur darin, daß sie das Ziel: „gänzliche Vernichtung der empirischen Individualität and Verschmelzang derselben in die absolut reine Vernunftform oder Gott" als in der Zeit erreichbar setzen, während es nnendliche Anfgabe ist. Und erwägen wir, daß der Ersatz substituierter Totalitäten und Vollendungen durch bloB regulative Ideen, die Aufstellung unendlicher Aufgaben statt dogmatisch-metaphysischer Lösungen stets das methodische Wesen der kritischen Philosophie ansmacht, als deren rechtmäBiger Erbe sich Fichte fühlt, so können wir das Resultat in die Formel kleiden: der reine Moralismus in der Konstraktion der Wissenschaftslehre ist kritische Mystik.

II. Das Problem des Materials der Pflicht. Die metaphysische Wendang.

Die Dedaktion, die ein seelisches Phänomen konstruiert, kann letzthin nur dadurch vollkommen beglaubigt werden, daß gezeigt

1) IV, 147.

2) IV, 148. 
wird: das Begriffssystem, in welches sie auslänft, bilde wirklich die problematische, seelische Realität, bloß in begrifflicher Umformung, ab, es enthalte nicht nar alle Elemente des seelischen Gebildes, sondern bringe auch alles Charakteristische der Beziehungen zwischen ihnen zum adäquaten Ausdruck, es gleiche ihm noch in allen Imponderablien der Struktar und, nicht zuletzt, in der immanenten Dialektik, die in ihm wie in jedem geistigen Gebilde ist. Ist also wirklich das System der Sittenlehre von 1798 die adäquate Konstraktion des reinen Moralismas and tritt, wie unterstellt wurde, im materialen Problem dessen Dialektik zatage, so muß der Begriff des Materials der Pflicht, wie er bisher den Zielpunkt der Deduktionen bildete, so jetzt den Ansatzpankt für die Auflösung und Weiterentwicklung der Fichteschen Philosophie bilden. Und es müssen sich zwei im Fortgange anseres Problems notwendige Geschäfte mit einem Schlage erledigen lassen: die erste Sittenlehre von diesem Centralbegriff aus noch einmal vertieft zu überdenken und den logisch-genetischen Übergang zar zweiten za finden.

Zu diesem Zwecke sei die Frage gestellt, was zwischen dem reinen Willen and der Welt seiner Materialisierungen für ein Wertverhältnis besteht (bisher war von den logisch-systematischen Beziehungen der beiden Stücke die Rede). Dieses Wertverhältnis kann aus dem Phänomen des individuell-empirischen Charakters, in dem die zwei Welten am unmittelbarsten aufeinandertreffen, abgelesen werden. In ihm ist es nun ohne Frage so bestellt, da $B$ der reine Wille dem Ich absolut wesentlich ist, Ichheit überhaupt erst begründet, während der Naturtrieb, wenigstens als gerade so bestimmter Trieb ihm zafällig ist und mit seinem absoluten Wesen nichts za tan hat; daß also dieser nicht nur transzendentalphilosophisch sekundär, sondern anch wertmäßig ein Minderes, fast (als Einschränkung) ein Negatives darstellt. Der Trieb auf Selbständigkeit geht auf Selbständigkeit der Vernunft überhaupt, alle Individualität ist im sittlichen Endziel ausgelöscht. Individualität hat für die Sittenlehre anf ihrem höchsten Standpunkt allein diese Bedeutang: daß sie für uns Sinnenwesen ausschließliche Bedingang der Kausalität des reinen Willens, alleiniges Werkzeug und Vehikel des Sittengesetzes ist. Der ganze reale Mensch mit seinen Neigangen, Talenten, Energien hat keinen anderen Wert als diesen. Es versteht sich, daB alle Realität außer ihm erst recht keinen anderen Wert hat als diesen: ein zn- 
fälliger modifizierbarer Stoff für den Fortschritt des sittlichen Prozesses zu sein. Die Welt geht, ohne den geringsten EinflüB auf Sittlichkeit oder Unsittlichkeit za haben, nach ihren ewigen Gesetzen ihren Gang, „nm der Freiheit eine Sphäre zu bilden " 1). Sie muß mir werden was mir mein Leib ist: Werkzeng des sittlichen Handelns, dann ist ihr Sinn erfüllt.

Aber die Entwertang des Materialen geht weiter, muB weiter gehen. Der Stoff ist nicht nur gleichgültig sondern widerspenstig. Das Werkzeng hat einen eigenen Willen, zam mindesten eine sündige Sprödigkeit. Die Grundlaster der Trägheit, Feigheit and Falschheit hängen dem empirischen Menschen als Natur an: sie gehen aus der Tatsache der Endlichkeit überhaupt hervor. So ist alles Geschöpf unheilig und unrein ${ }^{2}$ ), dazu da überwunden zu werden. Selbst mein natürlicher Selbsterhaltungstrieb, wenn ich ibn mir auch als meine Natur zarechnen maB, ist mir im Grande etwas objektives, fremdes, uneigentliches, gegen das ich mich zu wenden habe. Was mir eigentlich ist, mein reiner Wille, reißt sich von aller Nator los, bestimmt sich ganz unabhängig von ihren Antrieben, erblickt sie also tief unter sich als etwas was er nicht achten kann: ein Entschla $\beta$ and er ist über sie erhaben ${ }^{\%}$. Alles dies ist, darauf kommt es an, nicht Fichtes persönliches Bekenntnis oder zufälliger Geschmack, sondern im deduzierten Begriff des Materials der Pflicht als notwendiges and, wie sofort erhellt, dialektisch wirkendes Moment enthalten. Man maß sich nämlich überlegen, was alles in einer Ethik, die das Materiale konsequent entwertet, ethisch irrelevant oder ethisch negativ wird. Schlechthin alle Strukturzasammenhänge und Kontinuitäten verfallen diesem Schicksal. Denn der reine Wille, der anßer der Zeit and absolut einfach ist, bricht wohl anf unbegreifliche Weise für Momente durch, aber nur Natürliches dauert und hat ein Gefüge ${ }^{4}$ ).

1) $\nabla, 184 / 5$ (Grund unsres Glaubens).

2) IV, 204 (Sittenlehre).

3) IV, 142 (Sittenlebre).

4) $\mathrm{DaB}_{\mathrm{a}}$ der individuelle Charakter, als Kontinuität und Struktur, von dieser Ethik nicht als Wert erfaßt werden kann, ist demnach nur ein Spezialfall der allgemeinen Schwierigkeit, freiligh ein besonders wichtiger. Denn er räumt mit dem Begriff der intelligiblen Individualität auf, den er als logische Unmöglichkeit erkennt, sobald er sich auf das formallogisch abstrakte Wesen des einzigen ethischen Wertes bẹsinnt. Die selbstrerständlich immer wieder einsetzende Bemühung, Charakter, Persönlichlieit und ähnliche Werte höherer Struktur begrifflich 
Das Korrelat zur Entwertung aller zeitlich-straktarellen $\mathbf{Z}_{\mathbf{u}}$ sammenhänge bildet die reine Momentaneität and sporadische Art des Sittlichen. Die sittliche Handlung geht hervor ans einem absolut ersten, unerklärlichen, momentanen Eingreifen des reinen Willens. Dieser Eingriff gilt nur für die eine Handlung, er erzeugt keine kontinuierliche, beständige Sittlichkeit - eine solche gibt es nicht. Sondern Sittlichkeit ist ein beständiges Wiederansetzen des reinen Willens, enthält daher die Forderung immer en vedette za sein (denn es kommen immer neue Lagen) und das $\mathrm{Be}$ waßtsein der Pflicht immer anfs Nene in sich wachzarufen. „Niemand ist seiner Moralität ohne fortgesetzte Anstrengang einen Augenblick sicher. Kein Mensch wird im Guten bestätigt “ ${ }^{1}$ ). Die Unbegreiflichkeit dieser mit einander garnicht zusammenhängenden momentanen Entschließung verführt Fichte zu Gedankengängen, in deren Seltsamkeiten nnd Inkonsequenzen die Hoffnungslosigkeit des Problems zum Ausdruck kommt. Wie sich zum erstenmal aus dem kansalen Flu $B$ des Empirisch-Seelischen and seiner natürlichen Trägheit der gute Wille erheben könne, das erklärt ex darch Einwirkang der "Muster", die die positiven Religionen aufstellen, „Veranstaltungen, die vorzügliche Menschen getroffen haben, um auf andere zur Entwicklung des moralischen Sinnes za wirken" ${ }^{2}$ ). In wirkliche Verwicklangen bringt ihn die Frage, ob nicht doch Garantien für das Fortdauern des Entschlusses zum Guten gefunden werden können. Er konstruiert dazu eine $Z$ wischenwissenschaft und moralische Kunstlehre (eine Paralelle zur Politik); die Asketik $^{3}$ ). Diese Wissenschaft steht von Anfang an vor einer gründlichen Antinomie: der freie Wille, der sittliche Entschluß steht in keiner Kausalität und soll doch nach Regeln hervorgebracht werden, es gibt in ihm nur ein Entweder-oder, nicht ein Fortschreiten, and doch soll methodisch za ihm hingeführt werden. Die Asketik bestimmt schließlich als ihren Gegenstand: die Mittel um den (einmal für immer gefaBten) Entschluß zur Pflicht stets in uns gegenwärtig $z \mathfrak{n}$ halten and findet die Assoziationsgesetze als Hilfen der Sittlichkeit. Nur daB eben der Akt der Freiheit, durch welchen man das Bewaßtsein der Pflicht in jedem Momente

einzufangen, sprengt die Voraussetzungen, macht also die latente Dialektik des Systems aktuell.

1) IV, 195.

2) IV, 205.

3) Nld. 1II, 119 ff. (Asketik, als Anhang zur Moral 1798). 
klar erhält, selbst ein (absolut erster, unerklärlicher) sittlicher Akt ist - der entscheidende Einwand gegen das ganze in sich widerspruchsvolle Unternehmen der Asketik. Gleichheit der logischen Struktur und, wie vorgreifend behauptet sei, ein tiefer geistesgeschichtlicher Zusammenhang verbindet dieses Problem Fichtes mit den praktisch-sittlichen Problemen der Mystiker and des klassischen Protestantismus. Auch da ist die Lage so, daB ein über alle psychische Kausalität erhabener, aus der Transcendenz stammender Erfolg (die Vereinigung mit Gott, das Bewaßtsein der Gnade, die Sicherheit auserwählt za sein) darch ein methodisches Leben, durch psychisches Training erreicht, erzwungen oder doch befördert werden soll. Religiöse Erfahrang and Genialität des mystischen Erlebens verdecken zeitweise die Schwierigkeiten der Theorie, die doch immer wieder bervortreten, Sektenbildungen oder Änderungen der Lehre erzeugend. Nennt nun Fichte die innere Arbeit, die das BewaBtsein der Pflicht wachhalten soll, Gebet und die Moralität Seelenheil, so sehen wir den ProzeB, der ein religiöses Problem, unter Beibehaltung der logischen Struktar, zu einem moralischen macht, gewissermaßen auf dem Wege and erkennen die Dialektik, die wir in Fichtes Philosophie wirken sehen, als ein Erbstück nicht nur des reinen Moralismus sondern des ganzen transcendenten Daalismus, dessen eine Phase jener ist.

Diese Dialektik maß sich anf ihre letzte Formel bringen lassen, wenn nach den Prinzipien gefragt wird, durch die der reine Moralismas die sporadisch in die Erscheinung tretenden Akte von Sittlichkeit za der idealen Einheit zusammenschlieBt, die sie ihrer transcendentalen Herkunft nach im Grande sein müssen. Das Materiale legt den reinen Willen nicht nar in die Zeitlichkeit sondern auch in die Vielheit empirischer Individuen auseinander, und wie jene Differenzierang das unlösbare Problem des individuellen sittlichen Charakters, so gibt diese die Probleme der sittlichen Gemeinschaften and des Ganzen der Sittlichkeit auf. Kant hat diese Fragen bereits gestellt, und wenn er sie auch scheinbar nar daza benutzt, am allerlei christlich-theologische Angelegenheiten za ordnen, seine Lösang ist doch im wesentlichen die notwendige Lösung des reinen Moralismus. Freiheit versetzt ans in eine ${ }_{n}$ intelligible Ordnung der Dinge", in eine ${ }^{\prime N a t a r}$ unter der Antonomie der reinen praktischen Vernunft", in ein ${ }_{n}$ Reich aus lauter Willen", - also in eine Gemeinschaft, die von den realen, 
materialbestimmten Beziehangen, in die wir sozial verwoben sind, toto genere verschieden ist. Was Fichtes Begriff eines Reiches der reinen Willen in der ersten Periode seines Philosophierens anlangt, so maß man bedenken, daB die Reihe der Schriften, welche die Wissenschaftslehre zum vollständigen System der neuen Philosophie determinieren sollten, mit der Sittenlehre von 1798 abreiBt, und $\mathrm{daB}$ die Religionslebre, die wie Rechtsphilosophie und Ethik der „Grundlage ${ }^{~}$ folgen sollten, aus äußeren Gründen nicht ge-

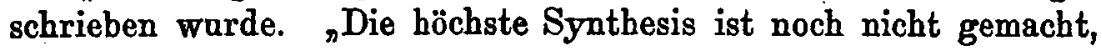
die Synthesis der Geisterwelt. Als ich Anstalt machte diese Synthesis zu machen, schrie man eben Atheismus" (Brief an Schelling vom 31. Mai 1801). So sind wir auf halb popoläre, ad hoc verfaBte oder apologetische Gelegenheitsschriften and anf Werke der Übergangszeit, also darauf angewiesen, eine ansetzende Systembildung, weil sie logisch notwendig ist, ans der viel komplizierter geschichteten, zadem in Bewegung befindlichen Gedankenwelt, die wir wirklich vorfinden, herauszulösen.

Es muB festgehalten and aufs nene betont werden, daB die Prinzipien der Erkenntnis and die sittliche Aufgabe von der Wissenschaftslehre ohne den Begriff des Individuums, rein vom Begriff des Ich aus festzulegen sind and festgelegt worden sind. Erst die relativ niedrigere Sphäre der Rechtsphilosophie braucht and leistet die Deduktion des Individunms ans dem absoluten Ich and die Konstraktion der realen Gemeinschaften zwischen den Individuen. Und wenn sich auch die Rechtsphilosophie im geschlossenen Handelsstaat za einem ethisch höchst bedentsamen Sozialismus erhebt, dies ihr letztes Wort ist längst nicht das letzte Wort, das die Ethik über die Synthesis der individuellen Sittlichkeiten zu sagen hat. Denn für sie steht es so: Mein sittlicher Wille ist über meine Individualität hoch erhaben, ich will nicht meine Unabhängigkeit, sondern Unabhängigkeit der Vernunft ïberhanpt. So ist es mir notwendig ganz gleichgültig, ob ich, das Individuam A, oder ob B oder C das Sittengesetz darstellt. Wenn es nar dargestellt wird, so ist mein Zweck erreicht, und mich hat es zum Objekt nar als eines der Werkzenge seiner Realisation in der Willenwelt ${ }^{1}$ ). Das ist der Denkznsammenhang, aus dem allein sich für das System der Sittenlehre die Pflicht ergibt in Gesellschaft zn leben ${ }^{2}$ ) and mit den übrigen die "Kirche“ d. h.

1) IV, 232 u. 237 (Sittenlehre).

2) IV, 234

ᄁ 
die Vereinigung $z a$ bilden, in der alle einander in ihrer Sittlichkeit befördern. Man darf sich nicht darüber tänschen, daß das nichts weniger als eine positive Wertang der Gemeinschaften bedentet. Pointiert ausgedrückt: ich soll in Gemeinschaft leben, nicht weil mir die Andern nnd ihre Gemeinschaft wiohtig, sondern weil sie mir ebenso unwichtig sind wie ich mir bin. Allein wichtig ist mir die Unabhängigkeit der Vernanft überhanpt, die nun einmal zanächst nur im gemeinsamen Streben der empirischen Individuen dargestellt werden kann. Aber das ist nicht die letzte Synthesis der Moralitäten. Wie die letzte Einheit der sittlichen Akte eines Individaums nach der Logik der Sittenlehre nicht der individuelle Charakter (weil er etwas material bestimmtes wäre), sondern jene ideale Reihe ist, die von materialer Gebundenheit za absoluter Unabhängigkeit führt, so müssen hier die empirischen Gemeinschaftsbeziehungen draaßen gelassen and die Akte and Aktreihen za einer rein intelligiblen Synthesis vereinigt werden. Ibre Konstruktion ist in den Schriften aus der Zeit des Atheismusstreites enthalten. Alles Wollen maB einen $\mathrm{Z}_{\text {weck }}$ and in der Realität und dem Weiterwirken dieses Zwecks Folgen haben, sonst wäre das Wollen sinnlos. Das sittliche Wollen ist davon nicht ausgenommen. Zwar als sittlich Handelnder sollst du schlechthin gehorchen, obne Rücksicht auf irgend einen $\mathrm{Z}_{w e c k}$; betrachtest da aber dein Handeln so denkst du notwendig eine Folge zar Moralität hinzu '). Aber diese notwendigen Folgen des reinen Willens können nicht empirische Wirkangen in der sinnlichen Welt sein. Denn was realiter aus meinem Handeln folgt, hängt nicht von mir sondern von dem unübersehbaren and um Sittlichkeit unbekümmerten Lauf der Welt $a b$; mein ist nur der Entschluß, der Erfolg sein. Selbst die höchsten Zwecke: die Veredelung der Gesellschaft, der Fortschritt des Menschengeschlechts, die Errichtung des Vernunftstaates, der Sieg des Guten auf der Erde (alles dasjenige, was die material gebandene Philosophie als die Bestimmang unseres Geschlechts aufstellt) ${ }^{y}$ ), ist nicht letzte Synthesis in den Augen der Sittenlehre, wenn sie das reino Reich des Zweckes sucht. Jene Dinge soll ich natürlich wollen, aber sie sind, wie alle irdischen Zwecke, Abgeleitetes ans Höherem, Durchgangsstadium auf dem Wege zur absoluten Unabhängigkeit;

1) V, 392 (Privatschreiben) u. II, 284, 286 (Bestimmung des Menschen).

2) Z. B. YI, 314 ff., 324 f. (Bestimmung des Gelehrten). 
and zudem sind sie, wenn es gelänge sie in die Realität einzafähren, nicht unser Werk, denn sie unterstehen der Kausalität der Natarkräfte. Vielmehr müssen die Folgen, die ich als den Sinn meiner pflichtmäBigen Handlungen fordere, rein als Folgen der Gesinnung, und der Zusammenhang, der sich aus ihnen erbant, als eine zweite Wirklichkeit mit einer zweiten Kausalität gedacht werden. Ich postaliere, das ist Religion, eine Welt, in der kein gater Entschlab verloren geht, and in der, weil kein eigengesetzliches Material die Wirkangen verfälscht, aus Gatem nor Gutes hervorgehen kann. Im religiösen Erlebnis, das sich aus tugendhafter Gesinnung von selbst erzeugt, geht dem glärabigen Gemüt diese Welt and ihre Gesetzlichkeit als nnmittelbare Gewißheit auf. „Erzenge nur in dir die pflichtmäBige Gesinnung und da wirst Gott erkennen" ${ }^{1}$ ). Dem Philosophen freilich ist aufgegeben, sie begrifflich zu formulieren, aus dem Wesen der Vernunft za deduzieren and ihren Ort im System za finden. Thr Ort im System ist gefunden: sie ist der notwendige Zweck des Menschen bei seinem Gehorsam gegen das Pflichtgebot. Die Arbeit ihre begriffliche Formulierung zu finden macht, wie man weiß, den philosophisch-systematischen Gehalt and das Erquickliche in der Unerquicklichkeit des Atheismusstreites aus. Die moralischeWeltordnnng, diese unmittelbare Realität für das gläubige Gemüt, kann vom Begriff nicht als seiend gesetzt werden, denn fiur die Wissenschaftslehre ist alles Sein notwendig ein sinnliches (sie leitet den ganzen Begriff erst aus der Form der Sinnlichkeit ab): ein seiender Gott wäre also für sie eine ränmlich existierende Substanz. Vielmehr muB aus den Begriffen Sein Gesetz Prinzip Welt Ordnung Gott, sollen sie für die Erkenntnis dieser Synthesis taugen, alle Bedeutung eines toten, ruhenden, stehenden genommen werden. Die moralische Ordnung ist tätiges Ordnen, ordo ordinans${ }^{2}$ ). Jede sittliche Handlung gliedert uns in diese lebendige Wirklichkeit ein, and die Philosophie faßt blos die Fülle dieser realen Beziehnngen zum Begriff der moralischen Ordnung

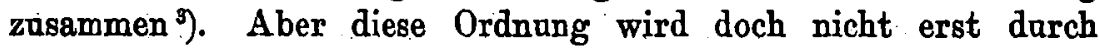
Gutestun hergestellt sondern ist ein unabhängig von unserm Handeln gültiger Zusammenhang, der ans and unsere Taten auf-

1) V, 210 (Appellation) V, 359 (Rückerinnerungen usw.).

2) V, $381 \mathrm{ff}$. (Privatschreiben).

3) V, $208 \mathrm{ff}$. u. $.360 \mathrm{ff}$. 
nimmt und auf den wir rechnen, wie der Säemann anf die Ordnung der Natur rechnet, die den Samen aufgehen lassen wird. Wie freilich diese zweite Natar und die Kansalität des reinen Willens in ihr näher zu denken sei, das zu begreifen mühen sich abwechselnd Begriff and anschauliche Schilderung $\left.a b^{1}\right)$. - Sie bestimmen sie etwa als einen allumfassenden Willen, der das geistige Band zwischen allen Willen ausmacht and auf den alle, als Vernunft auf Vernunft, unverfälscht ihre Wirkung ausüben. Jedenfalls gehört ihr der Wille nicht als materialbestimmtes Wollen sondern als reiner Entschluß an: sie ist eine Sphäre ohne ein Material der Pflicht, eine intelligible, zeitlose, stets gegenwärtige Welt.

So kennt die Wissenschaftslehre allerdings umfassendere $\mathrm{Z} \pi$ sammenhänge als die isolierten Phänomene des Pflichtbewußtseins. Allein in diesen Zusammenhängen liefert sie keine Konstraktionen der konkreten Ganzheiten der sittlichen Wirklichkeit sondern bant eine neue Welt aus lauter intelligiblen Tatsachen anf. Und es bleibt dabei, daß die Sittenlehre alle Kontinuitäten der sittlichen Welt draußen läßt, bestenfalls durch Kompromisse von ihnen Notiz nimmt, konseqnenterweise aber gegen sie als materialbestimmte Gebilde völlig gleichgültig ist. Za behaupten und za beweisen, dab diese kühne Negation riesiger Werttatsächlichkeiten nicht bloB ron Fichtes Philosophie, auch nicht bloB vom reinen Moralismus, sondern von dem Denk- and Lebenssystem, dessen Phasen beide sind, vollzogen wird, wäre eine weitläufige Angelegenheit and hiebe das Problem einer Genealogie und Dialektik des reinen Moralismus in Angriff nehmen. So kann hier nur mit aller Reserve der schon erwähnte Zusammenhang noch einmal angedeutet werden, daß in der mystisch-subjektivistischen Wendung der antiken Philosophie, ror allem aber im Christentum das gläubig-sichere oder ekstatische Wahrnehmen eines Transcendenten in der eigenen Seele zum entscheidenden Erlebnis wird; daB das nene Lebenssystem nar in einigen genialen Mystikern rein religiös bleibt, sonst aber auf vielen Wegen (besonders zu Beginn der Neuzeit) aus einer Religion zu einer Moral wird (wie z. B. die Herleitang der bürgerlichen Berafsethik ans dem Protestantismus der Reformationszeit durch Max Weber unternommen werden konnte), daß aber in allen Wandlongen die logische

1). II, 282 ff. (Bestimmung des Menschen). 
Struktur des Systems and seine immanente Dialektik erhalten bleibt, weil immer dieselbe Unbegreiflichkeit (wie das Transcendente nnmittelbar in die Zeit eingehen könne), immer derselbe Radikalismus des Wertens und Entwertens, immer dieselbe Unmöglichkeit, die realen Lebenszasammenhänge gelten zu lassen, obwaltet. Friedrich Nietzsche, der den $\mathrm{HaB}$ als Motiv in der Geschichte der Theorien entdeckt hat, hat, selbst mit den Angen des Hasses, den tiefen Zusammenhang zwischen allen Weltanschaunngen mit einer Hinterwelt aufs schärfste gesehen. Das Christentam gewöhnt die Menschheit an den „abergläubischen Begriff der Seele", an die unsterbliche Seele, die „eigentlich ganz wo anders zuhause ist und nun zufällig in diese oder jene Umstände, ins Irdische, gleichsam hineingefallen ist" ; sie macht das Individuum transcendent, „macht ihm den Größenwahn beinahe zur Pflicht", „löst es heraus aus Volk, Staat, Kulturgemeinschaft, Gerichtsbarkeit", "schliebt es durch eine Art Gefühlsidiosynkrasie $\mathbf{a b}^{\alpha}$. Die Moral aber erhält sowohl die „Verselbstangsperspektive ${ }^{4}$ wie die "Gleichberechtigung aller vor dem Ideal ${ }^{*}$ wie "den bösen Blick für das Wirkliche" aufrecht, und es gibt noch immer "lauter unsinnig wichtige Seelen, mit entsetzlicher Angst um sich selbst gedreht" ..... Alles krampf hafte Formeln für unleugbare Tatsächlichkeiten, die in dem gedanklichen ProzeB, den wir innerhalb der Fichteschen Philosophie verfolgen, das Treibende sind. -

Die Weiterentwicklung der Fichte'schen Sittenlehre rein immanent moralphilosopisch erklären zu wollen (wozu bisher der Grund gelegt wurde), ist natürlich eine Unmöglichkeit, so berechtigt es auch nach dem ganzen Charakter des Fichte'schen Denkens erscheinen muß, die praktisch-philosophischen Probleme zunächst einmal als die weitertreibenden anzusetzen. In Wirklichkeit bewegt sich, wenn sich ein philosophisches System ändert, das ganze System, and diese lebendige Dynamik von der Entwicklang eines einzigen Problemes aus za erklären, würde denselben methodologischen Fehler einschließen, den etwa der historische Materialismus enthält. In unserm Falle kommt hinzu, daB die in Rede stehende Wandlung chronologisch zuerst in der Wissenschaftslehre nachweisbar ist, dann in halbpopulären Kultur- und religionsphilosophischen Schriften durchgeführt wird und erst zuletzt die systematische Ethik ergreift. So ist der nächste Schritt, der von uns zu tun ist, zagleich durch den Stand der Quellen and durch die Natur des Problems gefordert. Es muß festgestellt werden: in- 
wiefern die nede Wissenschaftslehre eine neue Ethik mit sich bringt and inwieweit diese Antriebe, die gewissermaßen von oben kommen, mit den Antrieben von innen in einer Richtung wirken.

Diese Feststellang ist nicht leicht. Man weiB, daß die Historiker der Philosophie nicht einig sind, ob mit der Wissenschaftslehre von 1801 wirklich ein neues System einsetzt, oder ob sich bloB innerhalb des alten einige Accentverschiebungen vollziehen. Zadem verschwinden nicht einfach die alten Lehren, sondern sie dauern innerhalb and anterhalb der neuen fort, bereichern das entstehende System, komplizieren es aber auch und erzengen Widersprüche oder laden doch die neuen Begriffe so mit Schwierigkeiten, daB hier durchans schematisiert werden maB, soll ein formalierbares Neues ans dem Alten überhaupt herausgehoben werden. Schematisch läßt sich die Wandlung so ausdrücken, daß eine unaufhaltsam ins Metaphysische gehende Tendenz (gleichsam ein neuplatonisches Schicksal) das Fichte'sche Denken zu immer höher gelegenen Ansatzpankten der Dedaktion hinanftreibt and über dem System der abstrakt-allgemeinen Notwendigkeiten der Vernunft die konkrete Allgemeinheit der vollendeten Wissenstotalität, über dem teleologischen Zusammenhang des Wissens einen metaphysisch-realen Zusammenhang des Seins erschafft ${ }^{1}$ ). Der formallogische Wandel des Allgemeinheitsbegriffes (an Stelle der abstrakten Allgemeinheit der transcendentalen Form tritt die konkrete Totalität der das einzelne als Teil enthaltenden Idee) entspricht auf das vollkommenste dem Fortgang der Wissenschaftslehre von transcendental-philosophischen Deduktionen za bald spinozistischer bald emanatistischer metaphysischer Systematik ${ }^{2}$ ). In die nähere begriffliche Bestimmung des metaphysischen AbsoInten, das jetzt an die Spitze des Systems tritt, geht freilich die ganze idealistische Begriffsbildung der früheren Wissenschaftslehre ein und scheidet die entstehende Metaphysik von allem Spinozismas. Das Absolute ist durchaus kein Sein oder darf doch nur mit allem Vorbehalt so genannt werden, weil dieser Begriff für den Existenzcharakter der sinnlich-empirisch-materiellen Welt

1) Diese Hypostasierung des Ganzen des Wissens zur metaphysischen Realităt ist prinzipiell ausgesprochen z. B. II, $105 \mathrm{ff.}$ : Aber es wäre natürlich Willkür, ein Philosophem, das den Kern aller Schriften dieser Periode bildet durch einzelne Citate $2 \mathbf{u}$ belegen.

2) Diese Entsprechung nachzuweisen ist das Thema des Lask'schen Buches über Fichtes Idealismus und die Geschichte. 
festgelegt ist. Es ist "Sein" nicht als Objekt irgend eines Wissens, sondern als Möglichkeit and Ursprang alles Wissens. Es ist newig ans sich selbst quellendes Leben und Grundsein seiner selbst ${ }^{4}{ }^{1}$, jedenfalls unendliche Agilität, nicht zu stehendem Produkt verfestigt. Dies gegen Spinoza: „Das Sabstanzenmachen ist eine vis enertiae des Wissens. Die Wissenschaftslehre hat diese za vernichten, um das Leben selbst vor dem Blick zu fördern " z).

Auch das weitere ist gegen Spinoza festzuhalten ${ }^{3}$ ), dab das Absolute (Gott) nicht gleich der Welt ist. Die Welt ist vielmehr bloßes Objekt, und der Übergang vom Absoluten zam Endlichen vollzieht sich nicht vermöge einer erkennbaren Notwendigkeit sondern wird vollzogen durch die formale Freiheit des Wissens: aus ihr geht die Vervielfältigung and Verendlichung des Absoluten zur Welt, als begleitende Grundform des Wissens, hervor. In diesem höchst idealistischen Sinne, durch Vermittlung der Freiheit, gilt der Satz, daB nur Gott is $t$ and alles andere nur in der Erscheinung desselben and zafolge seiner ewigen Erscheinbarkeit existiert. Das $\mathrm{Bew}$ abtsein ist es, in dem das Absolute seine Verwandlung aus rein aktuellem, unmittelbarem and kräftigem "Dasein" zum qualitativ besonderten mannigfaltigen „Sein" der Welt erfährt").

Trotz dieses idealistischen Einschlags steht die Metaphysik der Wissenschaftslehre natürlich zu gaterletzt vor allen Schwierigkeiten des spezifischen Problems der Metaphysiker: wie das Verhältnis zwischen Metaphysischem and Empirischem sei, und wie das Absolute daza komme sich zu verendlichen, sich za änßern, za erscheinen. Fast alle Gleichnisse und Begriffsbildungen, die die Geschichte der Metaphysik zar Lösung dieses Problems gefunden hat, kehren bei Fichte wider: Plato und der Neuplatonismus, die Mystik and Spinoza klingen an. Oft versinkt ihm die Realität des einzelnen in derjenigen der Totalität und der ProzeB des Sichäußerns des Absoluten wird so stark phänomenalisiert, dab die Welt ans einer Erscheinung zu blobem. Schein and das mannigfaltigkeiterzengende Wissen zn einer Quelle der Täuschnng wird: beides führt die Wissenschaftslehre an die Grenze des Eleatismus. Aber gegen diese Radikalisierang der universalistischen

1) NW: I, 74 (Tatsachen des Bewabtseins 1810).

2) NW. I, 75

3). Siehe etwa. II, 86 ff. (Wissenschaftslehre von 1801).

4) V, $454 \mathrm{ff}$. (Anweisung). 
Metaphysik streiten wiederam alte Gedanken der Wissenschaftslehre, die nicht aufgegeben sind sondern der neuen Form der Lehre dienstbar gemacht werden. Wie nämlich die qualitative Bestimmtheit des Wirklichen für Fichte von Anfang an rein faktisch, nnableitbar, irrational, „transzendental zufällig" war, so ist jetzt, nachdem das transzendentalphilosophische Problem des Individuellen zum metaphysischen Endlichkeitsproblem geworden ist, das Verhältnis zwischen Absolutem and Empirischem, zwischen dem göttlichen Leben und seiner Änßerung zwar ihrem Daß nach begreiflich, ihrem Wie nach aber anbegreiflich, und das Individnelle bleibt so irrational wie zuvor ${ }^{1}$ ). Irrationalität für die deduktive Erkenntnis deutet sich aber in einem metaphysischen System gleichsam antomatisch in eine gewisse reale Selbständigkeit des Unableitbaren am: so gibt jene transzendentalphilosophische Überzeugung ans der ersten Phase seines Systems Fichte die Handhabe, in dessen letzter Phase dem Individuellen and Materialbestimmten eine metaphysische Wirklichkeit and Wertigkeit zuzuerkennen, die für alle ans dem alten Begriff des Materials der Pflicht entwickelten Probleme neue Lösungen bereitstellt.

Denn nachdem über die neue Form der Wissenschaftslehre in ihrer logischen Struktar dieses Allgemeine vorausgeschickt worden ist, kann bewiesen werden: daB sie eine Metaphysik der Sittlichkeit und zwar einer Sittlichkeit, die über den reinen Moralismus energisch hinausweist, mit sich führt. Es sei noch einmal an das entscheidende idealistische $Z$ wischenglied in Fichtes Metaphysik, die formale Freiheit des Wissens, erinnert. Das absolute Sein äußert sich zanächst in der Form des Wissens, des Bewußtseins; and die materielle Welt ist wiedernm blobe Erscheinnng für das Bewaßtsein, vom Wissen hingeschantes Nichtich, also Phänomen im zweiten Grade. Das Ganze ist ein dreistufiges System metaphysischer Dignitäten, und das Wissen allein steht zum Absoluten, als seine unmittelbare Äußerung in direkter Beziehang. "Nar in der Form der Freiheit (des BewaBtseins) ist Gott sichtbar - - wie er überhaupt sichtbar ist: im Bild, im Gesicht" "). DaB Gott sich in einem Sein äaßere, ist antike Philosophie, daß er sich in der Freiheit äuBere, Wissenschaftslehre ${ }^{3}$ ). Der ideale Entwicklnngsproze $B$ des BewaBtseins, den die Wissen-
1) Siehe dazu Lask 185.
2) Staatslehre 520 .
3) Ebda. 
schaftslehre genetisch konstruiert, ist zugleich der Prozeb des Erscheinens und der "Selbstdurchdringung" Gottes. Und zwar ist Bewabtsein notwendig individuelles Bewußtsein. Das Absolute geht also um des Prozesses seiner Selbstdurchdringung willen notwendig in die Form einer Mehrheit von Individuen ein, es gibt ein Wissen Gottes von sich selbst nar innerhalb der menschlichen Intelligenzen. So ist die Individuenwelt das einzig Wahre nnd Wirkliche an der Natur, and mit ihrer Hervorbringung ist die allgemeine Geschichte der Natur geschlossen und zu Ende ${ }^{4}{ }^{1}$ ). Die materielle Welt ist Tat des individaierten BewuBtseins and hat mit dem Absolaten nichts za schaffen; aber sich in Bewaßtseinen zu individuieren ist Tat des Absoluten; „das Menschengeschlecht ist allein $\mathrm{da}^{\circ}$.

Warum es kein unindividuelles Bewußtsein und warum es nicht blob ein Individun sondern eine Mehrheit von Individuen gebe, mit diesem Problem hat es ja die Wissenschaftslehre von Anfang an za tun gehabt. Sie nannte das die Deduktion der anderen Iche und leistete sie in der Rechtsphilosophie ${ }^{2}$ ), indem sie das Vorhandensein eines Ichs anßer dem Ich als Bedingang der Ichheit überhanpt (in demselben Sinne wie etwa die Sinnenwelt) dedazierte. Freilich gelang damals nur die Deduktion eines andern Ichs und, näher zugesehen, war der Gegenstand der Wissenschaftslehre in ihren prinzipiellen Partien nicht die Ich-Indivi-

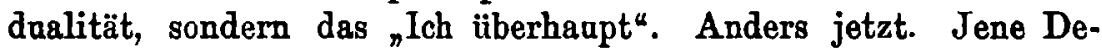
duktion ist charakteristischer Weise aus der Rechtsphilosophie in die Metaphysik der Sittlichkeit herübergenommen, zudem erweitert and metaphysisch vertieft worden. Einheit, so argamentieren die Tatsachen des Bewabtseins von $1813^{3}$ ), ist letztes Ziel der Vernunft, darf also nicht von Anfang an real sein: so erscheint das Absolute, wenn es sich zu Wirklichem (nnd zwar zu BewuBtsein) veräußert, nicht als Einheit eines Bewußtseins (es gibt kein universelles Ich, diese Stufe überspringt das Absolute gewissermaßen), sondern durchans als Mannigfaltigkeit, also als Gemeinde ron Ichen. Die vertiefteste Form der Lehre von der Individuation ist dies: das Absolute, das anendliches Leben und unendliche Kraft ist, maB deshalb in individueller Form erscheinen, weil es zu einer

1) II, 665 (Tatsachen des BewuBtseins v. 1810).

2) III, 30 ff. (Naturrecht).

3) NW. I, $517 \mathrm{ff}, 545 \mathrm{ff}$. 
wirklichen $\ddot{\text { A }}$ Berang seiner Kraft kommen will. Denn Handeln heißt Fortgang der Kraft von Leistung zu Leistung, also Aasgang ron einem bestimmten Ansatzpunkt aus. Nur in der individuellen Form ist das Leben praktisches Prinzip: um praktisch sein za können, kontrahiert sich das Absolute in individuellen Punkten von Kraft ${ }^{1}$ ). Nan aber ist das Absolute unendliches and anerschöpfliches Leben, der ProzeB seines Erscheinens muß also eine unendliche Produktion von Ichen sein. Damit hat sowohl die Tatsache der Individuation wie die unendliche Vielheit der Individuen, mit beidem aber das Menschengeschlecht, „das allein da ist ${ }^{4}$, seinen Ort im metaphysischen System erhalten.

$\mathrm{DaB}$ ich in mir ein Metaphysisches habe and erfasse, ist für die Wissenschaftslehre keine neue Erkenntnis. Aber daß dieses Metaphysische gegen die persönliche Individualität, die ich bin, keineswegs gleichgültig ist, auch nicht bloB sein Material an mir hat, sondern dab es in mir and den anderen Ichen, jedenfalls also wesentlich und ansschließlich in Individualitäten seine Existenz hat and $\mathrm{daB}$ nicht ein einschränkendes and verfälschendes Material sondern seine eigene Produktivität uns als Individualitäten aus $\mathrm{ihm}$ hervorgehen lieB, - das ist die neue und, wie man sofort sieht, für die anfgewiesenen ethischen Probleme entscheidende Lehre. Ich bereite den neuen Begriff des Materials der Pflicht vor, indem ich seinen Korrelatbegriff (den Begriff des reinen Willens, der reinen Sittlichkeit) in der nenen Form entwickle.

Als Gottes direkte Äußerang and ${ }_{n}^{\text {absolate Sichtbarkeit }}{ }^{4}$ ist das BewnBtsein lautere Lebendigkeit: nur in Lebendigkeit kann das absolute Leben erscheinen. "Fin Schauspiel ist es von freier Tätigkeit und Kraftänßerung, bloß and lediglich damit Kraft erscheine und Freiheit als Freiheit sichtbar werde ${ }^{4}{ }^{2}$ ). Wir fragen nun, ob dieses Schauspiel noch einen $Z$ weck habe auBer dem, daB es als Ganzes Bild des Absoluten ist, und ob im BewaBtsein eine Struktar za finden sei. Dazn ist zu erinnern, daB der lebendige FluB der Bewaßtseinswelt nicht das absolute Leben selbst, sondern nar seine Veränßerang zam Bilde ist. Zeitlichkeit, Aktualität and Werden sind Bestimmtheiten des empirischen "Lebens", das absolute "Leben" ist über ihnen wie über aller Bestimmtheit and wird, da doch nar mit Worten von ihm geredet werden kann,

1) II, 639 ff. (Tatsachen des BewaBtseins 1810).

2) II, 665 . 
in den mystischen Schriften als Leben, Liebe oder Seligkeit, in den philosophischen (mit Vorbehalt and im Gegensatz za dem FluB des Empirisch-Seelischen) als Sein bezeichnet. Die Struktar des BewaBtseins ist also so, dab es als Werden erscheint, dab aber ein Sein diesem Werden zngrande liegt. Man sieht, da $B$ diese Konstellation rein formal betrachtet dem Verhältnis zwischen dem reinen Willen and dem empirischen Charakter wie es sich in der Sittenlehre von 1798 ergab, nicht nnähnlich ist. Wie dort so erzeugt hier das dem Werden zugrande liegende metaphysische Sein als seine Synthesis mit dem Empirischen das Phänomen des nach einem Ziele gerichteten Werdens; den Erlebnischarakter des Sollens, die Tatsache der Sittlichkeit. So sind wir im sittlichen Handeln Gott am nächsten und am meisten aus Erscheinungswesen zu unserer metaphysischen Wesentlichkeit erhoben, Sittlichkeit ist, wie zuvor, die Substanz unseres Lebens und konstituiert wie unsern Wert so unser Sein.

Non aber zeigt sich, wie wichtig (bei aller formalen Äbnlichkeit der Begriffsbildangen von früher und von jetzt) in der neuen Metaphysik der neue Gedanke ist, daß das Absolute übergreifendes Ganzes, nicht mehr abstrakte Form ist nnd die Individuationen als seine wesentlichen Erzengnisse and Glieder umschlieBt. Der Prozeb, vermöge dessen das Absolute sich zu selbstbewuBten Individuen kontrahiert, vollzieht sich nämlich in der ganzen Breite and Tiefe des Bewnßtseins and seiner metaphysischen Grandlage and ergreift daher anch die Substanz des Seelischen, die Sittlichkeit. Nicht nur das aktuelle Leben, das Erscheinung ist, auch das zagrunde liegende Sein, das die teleologisch-ethische Struktur erzengt, untersteht dem Gesetz der Individuation: die Kontraktion des Absoluten auf Einheitspankte von Kraft ist zagleich eine Kontraktion auf Einheitspankte des Sollens ${ }^{1}$ ), and wie nicht ein universelles Bewaßtsein sondern eine Unendlichkeit selbstbewußter Individualitäten Realität hat, so hat nicht ein Endzweck, sondern eine Unendlichkeit individueller Bestimmungen Geltung; das Absolute aber ist Urgrund und Totalität beider Unendlichkeiten. Das ist der Punkt, an dem das Fichte'sche System eine philosophische Erfassung der Individualität za leisten fähig wird. Es ist zugleich der Pankt, an dem die neue Wissenschaftslehre in die neue Ethik

1) II, 663 (Tatsachen des BewaBtseins 1810). NW. I, 520 n $n$ 1813). 
übergeht. Durch den ProzeB seines Erscheinens erleidet das Absolute eine zweifache Veränderung, durch die es aus dem Objekt der Metaphysik zum Objekt der Sittenlehre wird: es wird (durch seine Synthesis mit dem Werden) aus rahendem Sein zam Endzweck des Werdens und (durch das Gesetz der Individuation) ans einheitlichem Zweck zar Mannigfaltigkeit individueller Aufgaben - das aber ist das Phänomen der sittlichen Welt.

\section{Die Sittenlehre von 1812.}

Das System der Sittenlehre von 1812 ist nur äußerlich ein weniger systematisches Werk als das System der Sittenlehre von 1798. Es ermangelt natürlich, weil es nicht vollständig ansgearbeitet ist, der letzten Formung, aber es ist reich an ganz gereiften Formulierungen. Es zeigt nicht die strenge und komplizierte äußere Systematik der ersten Sittenlehre, die in Lehrsätzen und Beweisen aufgebaut ist, aber dieselbe Energie, einen rascheren Gang and die gleiche innere Gegliedertheit des Denkens. Aach ist es, wie bereits vorlänfig gezeigt werden konnte, mit dem philosophischen Gesamtsystem ebenso vollkommen in Einklang and durch dessen allgemeinste Prinzipien ebenso notwendig bedingt, wie die frühere Sittenlehre die innerlich notwendige Ethik der früheren Wissenschaftslehre ist. Und da zudem die Gedanken, auf die es uns ankommen wird, zwar ihren systematischen Ort in der Sittenlehre haben, aber auch in allen andern Schriften der gleichen Zeit auftreten oder doch vorausgesetzt sind, so gibt es keinen Grund, die nachgelassene Sittenlehre nicht als vollwertige Quelle gelten za lassen. $\mathrm{DaB}$ sie nicht gedruckt worden ist, soll (wie man Fichte kennt) kein Einwand gegen die Schrift sondern gegen das Zeitalter sein.

Wir gehen, wie im ersten Teile, nicht einfach dem Gedankengang des Systems nach, sondern grappieren wiederum seine Deduktion um das Problem des "Materials der Pflicht" and am die daraus erwachsenden Probleme der sittlichen Kontinuitäten (Charakter, Gemeinschaft, Geschichte), die das alte System ongelöst lieb. Weil nun die idealistische Konstruktion der Materie ebenso wie der Primat des praktischen Ich vor dem theoretischen aus der alten W'issenschaftslehre in die neue darchans übernom̄men, nur eben metaphysisch überbant worden ist, so bleibt für die mate rielle Welt der alte Begriff des Materials der Pflicht in voller Geltung. Metaphysisch gesehen ist die Natur die letzte Sphäre 
des sich emanatistisch änßernden Absolnten, Erscheinnng des Bewnßtseins das selbst bloß Erscheinung ist, änßerste Änßerlichkeit. Ethisch gesehen (denn der metaphysische Stufengang ist infolge des. Primats der praktischen Vernunft zugleich ein Stufengang von Bedingungen der Sittlichkeit, das ganze System ein ethischer Pantheismus) ist die Natar niedrigste und leerste Bedingang der Sittlichkeit, bloBe "Ersichtlichkeit" und "Vorstellbarkeit" der Freiheit ${ }^{1}$ ), notwendige empirische Hülle des Übersinnlichen der Sittlichkeit ${ }^{2}$ ), Sphäre, auf die die Freiheit ihre Wirkungen aufträgt and nur um ihrer Bildbarkeit willen gesetzt, Material der Pflicht im alten Sinne. Freilich kündigt sich schon hier in dem ethischen Begriff der materiellen Welt die Wandlang an: die empirische Natar ist nicht bloß Natur, viel Übersinnliches ist durch Bildung, Gesetzgebung, Wissenschaft, Religion in sie eingetreten and ,die Naturentwicklung immer mehr za durchdringen mit dem ïbersinnlichen Weltgesetze und sie ganz unter dasselbe gefangen za nehmen ist der Zweck anseres Daseins als Gattung " ${ }^{3}$ ). Gesellt sich nun daza der Gedanke, daß die jeweilige Gestaltung der Natur für den weiterschaffenden sittlichen Willen Grundlage seiner Arbeit and so jede produktive sittliche Leistang dadurch bedingt ist, daß die Erde durch die bisherige Geschichte das hentige Gepräge erhalten hat ${ }^{4}$ ), so ist die Natur aus der bloBen leeren Möglichkeit der Sittlichkeit zum werterfüllten Träger des sittlichen Fortschritts, das Material der Pflicht zum objektiven Geist geworden. Wie aber diese eminent historische Wendung genetisch-begrifflich zustandekommt, kann nur durch Aufzeigung der Entwicklung verstanden werden, die sich ganz im Innern des Begriffs Material der Pflicht und zuletzt im Begriff der Sittlichkeit überhanpt vollzogen hat.

Material der Pflicht, das ist für das System der Sittenlehre von 1798 nur eine Nance des Begriffs Materiale der Pflicht. Das heißt: alles Materialbestimmte des sittlichen Aktes hat mit dessen Sittlichkeit zu innerst nichts zu tun, ist logisch notwendige aber wertmäBig indifferente Bedingung ihres Erscheinens in der Empirie, ist nicht ihr Constituens, sondern ihr Material. Das Sitt-

1) Staatsl. 385.

2) NW. I, 511 (Tatsachen des BewuBtseins 1813).

II, 617 ff. » »

3) NW. I, 502/3.

4) NW. III, 154 (Bestimmung des Gelehrten). 
liche ist nor eines und ist, logisch gesehen, reine Form. Die Begriffspaare sittlich-aaßersittlich nnd formal-material decken sich. Alles Materialbestimmte and so alles Individuellgeformte kann Sittlichkeit enthalten, aber gerade seine Individualität entstammt prinzipiell nicht der sittlichen Sphäre sondern dem AuBersittlichen, das durch Einschränkung Individualität erzengt. Diese Coinzidenz von Material and Außersittlich gilt jetzt nicht mehr, das ist das Entscheidende. Denn jetzt steht es so: ein für die Wirklichkeit aller Grade geltendes Gesetz der Individaation prägt das Absolute, sobald es überhaupt ans seiner unfaßbaren Transzendenz heranstritt, zu lanter individuellen Gestaltangen um, die den Grand ihrer Existenz nicht in einschränkenden Einflüssen heterogener Sphären, sondern in der Schöpferkraft des Absolaten selbst haben. Sittlichkeit ist wie zavor ein Fremdling in der natürlichen Welt; aber sie ragt nicht mehr als die immer gleiche Form des reinen Willens, sondern in der vielfältigen and gegliederten Gestalt individueller sittlicher Bestimmungen ans derTranszendenz in die Empirie herein. Denn das eigentlich Metaphysische im sittlichen Akt ist, wie die Metaphysik der Sittlichkeit aufwies, jenes Sein, das den phänomenologischen Cbarakter des Sollens hervorruft: ihm aber ist die individuelle Form bereits wesentlich. Freilich konzentrieren sich gerade in diesem Pankte die begrifflichen Schwierigkeiten. Wir kennen jenes Sein nur aus seiner Synthesis mit dem Werden, nar aus seinen Wirkungen im realen Erlebnis, and hier ist es selbstverständlich individuell bestimmt. Aber die Metaphysik will die erlebte Wirklichkeit genetisch konstraieren, muB also das Sein vor der Synthesis und sein Hervorgehen aus dem Absoluten begrifflich erfassen. Die Schwierigkeit der Situation erklärt den Wechsel der Ausdrücke and den ringenden, approximativen Stil aller Partien, die dieses Problem behandeln. Ob aber das im sittlichen Akt zugrande liegende metaphysische Sein ${ }_{\text {Begriff }}{ }^{4}$, Bestimmung ${ }^{\prime}$ "Bild “ oder (mit deutlicherer Annäherung an den phänomenalen Befund) "Gesicht", "Zweck", "Sollen", genannt wird: nie wird über seine individuelle Bestimmtheit ein Zweifel gelassen. Das Absolnte spaltet sich a priori in eine Vielheit von überempirischen aber individuell bestimmten "Bildern": das ist die Welt, in der es am unmittelbarsten da ist. Es verteilt sich in dieser gespaltenen Form auf die Individuen, nimmt Besitz von ihnen und geht in ihnen, die bisher blobe Naturwesen waren, als ihr nener, schlechthin übernatürlicher Wille, als der „individuelle Charakter 
ihrer sittlichen Bestimmung" auf. Damit "setzt es sich in die Form des BewaBtseins" "). Bisher reines, ideales (wenn anch durchaus inhaltlich bestimmtes) Sein wird es nun: Vermögen des Wirkens, frei sich selbst bestimmende Kraft, karz: reales sittliches Handeln. Das Ich andererseits wird, indem das ideale Sein des Bildes sich in ihm „absetzt", sittliche Individualität, es ist als Natur aufgehoben und lebt nur noch als Leben und Kraft des Begriffes: das "Soll ${ }^{*}$ seiner individuellen Bestimmung macht den ganzen Sinn seines neuen Daseins aus. Also an der metaphysischen Herkunft des Sittlichen ist so streng wie nur möglich festgehalten: ein sittliches Ich ist Fleisch gewordene Vernunft, ein sittlicher Akt das Wirken des Absoluten in uns ${ }^{2}$ ). Aber nicht minder streng ist fixiert, daß der absolute Begriff, wie er im Individunm nlebt and erscheint", selbst schon eine materialbestimmte metaphysische GröBe, eine strukturierte Individualität ist. So kommt es nun daranf an (und das eben macht die empirische Individualität sittlich), daB der absolute Begriff in ibr ganz ersche in e. „Alle Erscheinungskraft dieses Begriffs muB wirklich und in der Tat erscheinen, ... dann ist die Erscheinang sittlich ${ }^{4}{ }^{3}$ ). Dasselbe vom empirischen Individuum ans gesehen: Sittlichkeit ist in einem Menschen realisiert, wenn das sinnliche Ich rein vernichtet und an seiner Stelle ein böheres, der Transzendenz entsammendes Individnelles zur Erscheinung gekommen ist, das „nur er sein kann und im Ganzen der Geisterwelt sein soll". Der kategorische Imperativ hat sich materialisiert and individualisiert, indem er sich metaphysisch konstruierte. "Wolle sein, was du sein sollst, sein kannst, bist" $\left.{ }^{4}\right)$ - in dieser Formel für die nene Sittlichkeit bezeichnet das "Sein " den durchaus individuellen Charakter der höheren Bestimmung, den in sich za realisieren die spezifische Sittlichkeit dieses Individuums ist. Wie das Individunm als natürliches für die kausale Weltbetrachtung sich nicht ändern kann, so ist es auch „in der sittlichen Welt, seiner moralischen Bestimmung nach, ohne sein Zatun oder Bewaßtsein schlechthin was es ist, und kann dieses nicht ändern: soll es auch nicht ändern, sondern nach dem Grundgesetz dieser Bestimmung mit Freiheit sich weiterbestimmen ${ }^{\alpha 5}$ ).

1) V, 531 (Anweisung) NW. I, 470 ff. (Tats. d. BewuBtseins 1813).

2) NW. III, $36 \mathrm{ff}$. (Sittenlehre von 1812).

3) NW. III, 43.

4) V, 533 (Anweisung).

5) II, 664 (Tats. d. BewuBtseins 1810). 
Dieser intellegible Determinismas ist die notwendige Folge der nniversalistischen Metaphysik and des Gedankens einer individuellen sittlichen Bestimmung. Die Entstehang eines Individunms (als sittlicher Individualität) ist ein besonderes und darchans bestimmtes „Dekret des sittlichen Geistes", der erst durch alle seine Dekrete sich vollkommen ausspricht.

Damit liegt im wesentlichen der gedankliche Prozeß zutage, der Fichtes Ethik von der Sittenlehre von 1798 zu der von 1812 führt, indem er ans der Tiefe der nenen Gesamtlehre die beiden Korrelatbegriffe des reinen Willens and des Materials der Pflicht so umwandelt, da $B$ in jenen eine materiale Bestimmtheit, damit aber ins Materiale der Sittlichkeit eine ethische Relevanz eindringt. Daß nun diese Wandlang die prinzipiellen Begriffe gerade zur Erfassung der sittlichen Individualität und zar Konstruktion der realen Zusammenhänge der sittlichen Welt geeignet macht, karz in einer Richtang länft, die der Dialektik der ersten Phase genügt, zeigte sich bereits ungewollt and wird sich in einer neuen Stellung gegenüber allen Problemen der sittlichen Kontinuitäten systematisch zeigen. Was also Lask im Rahmen seiner formal-logischen Problemstellung als Fortschritt der Fichteschen Lehre zu einer "logischen Erfassung der Wertindividualität" sieht, erscheint hier als prinzipielle Wandlung der ethischen Grundbegriffe and (falls diese Theorie über den Znsammenhang der sittlichen Wirklichkeit and ihrer ethischen Konstraktion gewagt werden darf) als prinzipielle Wandlung der sittlichen Weltanschaung, als Individualisierang und Historisierung des moralischen Wertes, als eine Auflösung jener Dialektik, die dem reinen Moralismus immanent ist.

Indem wir uns von der prinzipiellen Konstraktion des ethischen Phänomens zu den abgeleiteten Problemen erst der sittlichen Persönlichkeit, dann der Gemeinschaft und Geschichte wenden, wenden wir uns zugleich, nach der Logik der neaen Sittenlehre, von der Metaphysik zar Phän omenologi e der Sittlichkeit. Denn zwischen diesen beiden Teilen (oder Blickrichtungen) innerhalb ihres Gebietes unterscheidet die neuen Sittenlehre auf das Genaneste: die Einordnung der Sittlichkeit in den ErscheinungsprozeB des Absoluten macht ihr zar Pflicht, sich in jedem Moment bewaßt za sein, auf welcher Stufe dieses Prozesses sie ihr Objekt beobachtet. Und zwar macht die Tatsache der formalen Freiheit (das So-oderauch-anders-Können) die klare Grenzscheide zwischen den beiden 
Gebieten ans. Denn formale Freiheit hat nur in dem psychologischen, nicht in dem metaphysischen Dasein der Sittlichkeit, demnach nur in der Ethilk als Erscheinungslehre, nicht in ihr als Seinslebre eine Stelle. Das Einfließen der "Bilder" in die individuierte Kraft (also die metaphysische Genesis der Sittlichkeit) vollzieht sich gewiß in einer Welt von Freiheit, d.h. oberhalb der Naturkausalität. Aber diese „absolute Freiheit" hat nichts mit jener formalen Freiheit oder Indifferenz za tun, die eine bloße Erscheinungstatsache der Bewußtseinswelt, nicht im Sein sondern in der Sichtbarkeit des Seins begründet ist. Bisher trieben wir Theorie des Ich als eines Trägers des Begriffs, also Seinslehre. Unsere jetzigen Probleme führen uns in die Welt der Phänomene; wobei jedoch immer zu bedenken und als wesentlichster Erfolg des neuen Begriffs vom Material der Pflicht festzubalten ist, daB die sittliche Individualität einen metaphysischen Kern hat und, wenn sie anch jetzt von uns nach ihrer Phänomenologie angesehen wird, als Individualität eine metaphysische Tatsache ist und bleibt. Folgendes ist nun Fichtes nene Lebre über die Individualität.

Das unsittliche Ich ${ }^{1}$ ) lebt ein träges, zerfließendes Leben ohne innere Einheit, ja ohne eigentlich Aktivität; es kehrt der Welt keine Spitze zu; seine Taten geschehen mehr als daB sie getan würden und sind "eine zerstreute, nach mancherlei Nichts ringende Geschäftigkeit und Vieltuerei ${ }^{42}$ ). Einheit, Struktur and wirkliche Kraft kommt in dieses Leben erst hinein, wenn der Begriff von ihm Besitz ergreift. Durch ein ins Übersinnliche tragendes Erkenntnisvermögen, durch die "Sehe" erfabt das Individaum den Begriff, aber es ist richtiger zu sagen, dab der Begriff das Individuum erfaßt. Der neue Wille (denn als gerichteter Wille greift. der Begriff in die psychologische Welt ein) tritt non nicht etwa in Wechselwirkung mit dem bisherigen Naturwillen oder lenkt oder beschränkt ihn bloß: er hebt ihn vielmehr gänzlich auf und wird zum souveränen, vollständigen, einzigen Lebensprinzip des $\left.\mathrm{Ich}^{8}\right)$. Daß diese Aufhebung der Natur und Umformung unseres Selbst zum Leben des Begriffs erfolge, kann keine Freiheit er-

1) Es ist für den Fichteschen Persōnlichkeitsbegriff charakteristisch, daß er nicht als bloBer Strukturbegriff, sondern mit einer ethischen Wendung als Begriff der sittlichen oder der unsittlichen Persönlichkeit entwickelt wird. Darüber s. u.

2) NW. III, 59 (S. L.). NW. II, 160 (Bestimmung des Gelehrten). V, 494 (Anweisung).

3) NW. III, $86 \mathrm{ff}$. (Sittenlehre von 1812). 
zwingen. Es ist eine Wiedergeburt und so wenig ein Werk der Freiheit wie die erste Geburt ${ }^{1}$ ). Freiheit kann nar die Bedingangen der Wiedergeburt schaffen, indem sie sich vơ der Herrschaft des Naturtriebes losreiBt: „Arbeite an dir, dann arbeitet an dir Gott ${ }^{2}$ ). Unmöglich ist es nun für die begrifliche Analyse, den ganzen Gehalt der sittlichen Handlung, der sich durchans nicht mehr in der Tendenz auf Selbständigkeit erschöpft sondern im Einführen eines neuen "Gesichts" in die historische Wirklichkeit, in Prodaktivität besteht, za erfassen. Soll er geschildert werden, so stellt sich das Bild des schaffenden Genies ein, in dem anch eine aus dem Übersinnlichen entstammende Schöpferkraft zam - einzigen Affekt geworden ist and ein nenes "wesenhaftes" Ich inmitten des Natürlichen formt. Wie das geniale Tun enthält jeder sittliche Entschluß "Wesen", ein „Neues, Erstes, wahrhaft Freies" greift durch ihn in die Welt ein. Das setzt ihn gegen alles Handeln ab, das bloß der psychologischen Erscheinungswelt angehört. Von jedem sittlichen Tun gilt was von Pestalozzi gesagt wird: "Nicht er hat diesen Gedanken gedacht oder gemacht, sondern in ihm hat die ewige Vernunft ihn gedacht, und der Gedanke hat gemacht and wird fortmachen den Mann ${ }^{\text {(s). }}$ ).

Dieser metaphysische aber durchans inhaltlich bestimmte Kern des Sittlichen ist das entscheidende Moment im Begriff der Individualität, der im Fichteschen System erst hier, und zwar ethisch gefärbt: als Begriff der sittlichen Individualität entwickelt werden kann. Der reine Moralismus kannte diesen Begriff nicht, durfte ihn nicht kennen: er kannte nur einzelne sittliche Akte. Sittlichkeit war für ihn ein beständiges Wiederansetzen des reinen Willens in diskreten Momenten, ein beständiges Vernichtetwerden und Wiederaufleben des natürlichen Ichs, ein fortwährendes Streben: das Verbindende und Dauernde war die "Indifferenz" des freien Ich, das sich jederzeit nach allen Seiten entscheiden kann. Jetzt wird das Fortbestehen der formalen Freiheit geradezu zum Kriterium des noch nicht sittlichen Ich. „Kant hat die Sittlichkeit allerdings so beschrieben, and darin hat er Unrecht" "). Wenn der Begriff erst einmal vom Ich wirklich Besitz ergriffen hat, gibt es keine einzelnen sittlichen Akte mehr, sondern nur noch
1) NW. III, 41 (Sittenlehre ron 1812).
2) NW. III, 58.
3) NW. III, 267 (Gespräche über Patriotismus).
4) NW. III, 62 (S.-I.) 
einen ,absolnt einfachen. Willen", der den Natartrieb endgültig vermichtet hat and zum ewigen und zusammenhangenden Charakter geworden ist. „Es gibt keine sittlichen Handlungen oder dergleichen. Eine einzige Ausnahme von dem sittlichen Handeln zeigt, daB Sittlichkeit noch nicht da ist" ${ }^{\prime 1}$ ). Der Wille schwankt nicht mehr "frei ${ }^{\text {u }}$ zwischen Gut und Böse. Wer im einzelnen Fall noch wolle $\mathrm{n} \mathrm{maB}$, ist nicht sittlich; für den Sittlichen ist Freiheit des Willens in die Notwendigkeit anfgegangen. Der Wille wird nicht mehr and ringt sich durch, er ist und herrscht. Selbst der phänomenólogische Charakter des Sollens, der sich aus der Beziehung des reinen Willens auf die Natar ergab, verschwindet, weil keine Natur, die widerstehen könnte, mehr da ist. Das Individium lebt nicht mehr selbst, sondern in ihm lebt sein Endzweck; nicht als Sollen sondern als Wollen. Ganz prinzipiell gefaßt ${ }^{2}$ ): geht der Begriff in die zeitlich seelische Realität eines sittlichen Menschen ein, so $m a B$ er, da er ja doch einziges Prinzip dieser Realität werden soll, ihre ganze Zeit erfüllen. Das aber ergibt das Phänomen eines substanten, regelhaften, seienden Willens, and die Persönlichkeit kann definiert werden als „die Regel nach der sich in einem voransgesetzten Punkte die Zeit füllt". Schleiermacher hatte gegen das System der Sittenlehre von 1798 eingewendet ${ }^{8}$ ), daB sich in ihm das Ich seiner Unabhängigkeit darch bloße Hinzafügung einer Handlung zur andern, durch Akkumulation unzusammenhängender moralischer Handlungen annähere. Das war ein Einwand, dem durch Gewinnung eines Persönlichkeitsbegriffes begegnet werden konnte. Die im Inneren des Begriffssystems sich vollzièende Wandlang leistete das and leistete mehr: die konstraierte nicht bloß die Persönlichkeit als Straktarbegriff, sondern nabm in ihrer Idee des individaellen Charakters der höheren Bestimmung das Moment der „Eigentümlichkeit“ (das Schleiermacher in der ersten Sittenlehre natürlich ganz vermissen inubte) im System auf ${ }^{4}$ ).

1) NW. III, 55.

2) NW. III, 51 ff. (S.-L.).

3) Schleiermacher WW. III, 1, $31 \mathrm{ff}$.

4) Die neugewonnenen Begriffe wirken innerhalb des Fichteschen Systems weiter; dafür nur ein wichtiges Beispiel. Fichtes Lehre von der Unsterblich keit erfährt seit 1810 eine bedeutende Wandlung, im wesentlichen von dem neuen Persŏnlichkeitsbegriff aus. Vorher argumentiert Fichte für universelle Unsterblichkeit, indem er entweder, wie Kant, von der Unendlichkeit der sittlichen Aufgabe auf unendliche Existenz schlieBt oder, später, die Individuen als ursprüng- 
Einfache logische Überlegangen zeigen nan, wie eine Philosophie, die das Individaelle erfaßt, zugleich fähig und getrieben ist die konkreten $Z$ a sammenhänge des Individuellen, also Gemeinschaft und Geschichte, einzubegreifen. Solange nämlich die Begriffsbildnng auf allgemeine Begriffe aus ist, bleibt ihr nicht nur das einzelne Individuam, in dem sie einen bloben Verwirklichungsfall der abstrakt-allgemeinen Form zu sehen hat, sondern auch der konkrete Zusammenhang der Individuen unerfaßbar. Sie löst ja gerade das Einzelne aus den realen Totalitäten, deren Teil es ist, heraus, um es in die idealen Totalitäten aufzanehmen, die der Gegenstand ihrer abstrakt-allgemeinen Begriffe sind. Jede individnalisierende Begriffsbildung dagegen muß finden: daß der individuelle Gegenstand, den sie za erfassen strebt, nicht erfaßt werden kann, ohne seine (ihm als Individunm eigentümlichen) Beziehungen za anderen Individuen and seine Stellung in dem konkreten Ganzen, das ihn enthält, mitznerfassen. Die Einbezogenheit des Individuums in konkrete Totalitäten gehört zu seiner Individualität, und die konkreten Totalitäten selbst sind (formallogisch) Individuen - dies beides treibt die individualisierende Begriffsbildung and treibt Fichte in dieser Phase seiner Philosophie notwendig zu den Problemen von Gemeinschaft and Geschichte. Der historisch Zurückschauende weiß, wie sehr Fichte in den Bemühungen um diese Probleme mit dem stärksten Interesse seines Zeitalters, gegen das er sich so schroff abzusetzen liebte, im Einklang war und wie tief gerade seine Philosophie der Nation und der Geschichte in der lebendigen Wirklichkeit warzelte. Er weiß auch in welcher Mannigfaltigkeit von Gedankengängen sich diese Tendenz in Fichtes Philosophie auslebt: sie erzengt atopistische Bildangen neben praktisch-politischen Ideen, eine Pädagogik, die zwischen beiden in der Mitte steht, and eine universale Geschichtsphilosophie neben einer Geschichtsbetrachtung, die das

liche Kontraktionen des Absoluten, also als metaphysisch wohlbegründet und deshalb als ewig erklärt. Seit 1810 fügt er in dieso Gedankengänge den neuen Begriff der Persönlichkeit ein und zieht die Konsequenz: nur wer den metaphysischen Kern seiner individuellen Bestimmung in sich wirklich gemacht hat, ist für den Endzweck notwendig geworden; nur die sittlichen Individualităten sind ewig und gehen in die nächste Welt ein. (Dazu tritt in den letzten Schriften eine platonisch anmutende Eschatologie, die nach dem Untergang der gegenwärtigen Welt eine neue and so fort immer neue entstehen läBt, in deren jede nur diejenigen eingehen, die in den früheren den sittlichen Willen in sich erzengt haben.) 
Deatschtum absolat setzt. Aber nicht auf jene Zasammenhänge mit dem Zeitalter und nicht anf diese Mannigfaltigkeit der gedank: lichen Formen, sondern bloß auf die angedeuteten begriffsmäBigen Notwendigkeiten kommt es hier an, nach denen die sozial- und geschichtsphilosophische Wendung des Fichteschen Denkens in den prinzipiell-philosophischen Umwandlangen, die am Begriff des Materials der Pflicht aufgewiesen wurden, begründet sind.

Hierbei ist nun wichtig, dab der Fichtesche Begriff der Persönlichkeit rein mit ethischen Kategorien and rein zum Zwecke der Ethik konstruiert worden ist, and daB insbesondere jede Analogisierung zum ästhetischen Individuam fehlt (im Gegensatz zar zeitgenössischen Romantik, die in ihrer Philosophie der Individualität nie den Rekars auf die Einheit des ästhetischen Gegenstandes verga $B)$. Es ist klar, daB dem ethischen Persönlichkeitsbegriff das Moment der sozialen Einbezogenheit viel wesentlicher sein muß als dem ästhetisierenden. Dieser isoliert die Individualität als eine geschlossene and geformte Welt für sich, jener gibt ihr. eine individuelle Pflicht, also eine Funktion in einem Ganzen. So maB die sittliche Weltordnang, die die einzelnen Willen als ihre Glieder amschliebt wie die Natarordnung die einzelnen Naturwesen, der zweiten Sittenlehre Fichtes noch wesentlicher sein als der ersten. Aber dieser Begriff erfährt unter dem Einflaß der neaen Ethik dieselbe Materialisierang, die den Persönlichkeitsbegriff entstehen ließ. Wie der sittliche Wille nicht mehr reine Form sondern individueller Kern der konkreten Individuen, so ist die sittliche Ordnung nicht mehr Reich reiner Willen sondern metaphysische Substanz der konkreten Totalitäten: Gehalt and Bedentung der Staaten, Sinn und Gesetz der Geschichte. Der nene Begriff der $\mathrm{Nation}$ ist das erste begriffliche Prodakt der gedanklichen Wendung. „Die geistige Natur vermochte das Wesen der Menschbeit nar in höchst mannigfaltigen Abstufungen an Einzelnen und an Völkern darzustellen " ${ }^{1}$ ). Die Eigentümlichkeiten dor Nationen sind also so wenig zufällig oder durch äußere Einflüsse bestimmt wie die Eigentümlichkeiten der Menschen als sittlicher Wesen. Völker sind Dekrete des sittlichen Geistes wie die Charaktere, sie sind gewisse hochindividuelle Weisen den Vernunftzweck zu befördern ${ }^{2}$ ), sie haben einen metaphysischen Kern als

1) Reden an die deutsche Nation VII, 467.

2) VII, 563 (Polit. Fragmente). 
den individuellen Charakter ihrer höheren Bestimmang in sich. Erst dieser metaphysische Kern macht ein Volk zar Einheit, sowie erst durch den "Begriff" das naturhafte Einzelwesen zar Einheit der Persönlichkeit geformt warde. Jetzt können vom höheren Standpunkt ans alle Versuche, fremde sowohl wie eigene, verworfen werden, die Einheit einer Volksgemeinschaft naturrechtlich zu konstruieren. Nicht durch die Rechtsordnung, Verfassung und die anderen einheitschaffenden Formen kann die Einheit des Volkes begriffen werden (denn die Nation ist mehr als der Staat, der nur "Mittel, Bedingung und Gerïst für das Anfblühen ihres ewigen Gehaltes" ist) sondern allein durch den einheitschaffenden Inhalt des aus Gott hervorgehenden „Volkssinnes" oder „Volksgeistes", der das individuelle Selbst der Nation ist. Er macht das Volk eigentlich zum Volk, sein Fortschritt ist das Heilige in der Geschichte der Nation. Aus der Sprache kann man sein Wesen ablesen, aber vollkommen tritt er erst in den großen and außerordentlichen Momenten der Geschichte, in denen gewagt wird", ans Licht; nnd im gerechten Kriege um der Freiheit willen hat er seine unmittelbarste Existenz ${ }^{1}$ ).

Die bisher entwickelte Begriffsbildung setzt die Nation in rollkommene Paralelle zur Persönlichkeit. Auch Gemeinschaften können nach Gesichten handeln und sollen es, das gibt ihnen wie den Einzelmenschen zugleich mit ihrem sittlichen Wert ibre Einheit und Straktur. Der Begriff der Gemeinschaft kam also durch eine höchst fruchtbare Übertragung oder Erweiterung des Persönlichkeitsbegriffes, aber nicht eigentlich darch Integration der einzelnen Sittlichkeiten za einem konkreten Ganzen zustande. Erst im Begriff der Geschichte wird das Moment der Eingeordnetheit des Individuellen frachtbar gemacht und ein übergreifender Zasammenhang, ein Reich der sittlichen Werte konstruiert. Alle "Gesichte". gehen aus Gott hervor, aus Gott geht auch ihr Zusammenhang and der Fortgang von Gesicht za Gesicht hervor. Dieser Fortgang ist notwendig; „es ist das Gesetz der Freiheit eine gewisse Geschichte za bilden ${ }^{2}$ ). Der allgemeine Zusammenhang zwischen

1) Fine Parteilichkeit, mit dex man nicht rechten, die man nicht einmal bedanern wird, läbt Fichte seinen höheren Begriff der Nation nicht eigentlich allgemein sondern nur for die deutsche Nation ableiten, die er bald als Prototyp eines wahren Volkes, bald als das einzige wirkliche, ${ }_{n}$ schöpferische ${ }^{k}$ nnd ${ }_{n}$ wesentliche" Volk, als das „Volk schlechtweg" hinstellt, von dem alles GroBe bisher gekommen und ron dem allein die Fortführung der Geschichte zu erwarten sei.

2) Staatslehre 582. 
den Gesichten ist dadurch gegeben, daß jedes Gesicht erst in der Wirklichkeit dargestellt sein muf, ehe das neue kommen kann. Daher die ihm immanente Forderung real gemacht zu werden: das ist die Bedingung dafür, daB es za einem neuen Bilde kommt, daB Gott sich weiter offenbart, daß der Sinn der Geschichte weiter erfüllt wird. „Nur durch die wirkliche Tat gefragt, spricht die Erscheinnng der Gottheit sich weiter aus, nnd nach diesem Gesetz geht es fort ins Unendliche ${ }^{\prime \prime}$ ). Das ist der Begriff der Geschichte, der nun mit Fichtes Ideen über die Bestimmung des Gelehrten zu einer formalen Geschichtsphilosophie verschmilzt, die mir für ihn charakteristischer und philosophisch wichtiger erscheint als die bekannte Deduktion des Fünfstufenganges. Nar in der Verklärung Gottes rückt die Welt weiter, alles eigentlich Nene was geschehen kann ist die Erscheinung des göttlichen Wesens in einer neuen Klarheit, in einem neuen Gesicht. Ohne diese steht die Welt still, and es geschieht nichts Nenes unter der Sonne. Non haben an der Erscheinung der übersinnlichen Welt alle Menschen teil, aber den meisten bleibt das Übersinnliche gestaltlos, es durchdringt zwar ihr gewöhnliches Leben mit einem neuen Geist, treibt es aber nicht zu einer schöpferischen Tat an : die Masse ist bloB „religiös". Im "Gelehrten" dagegen (man weiß wie weit für Fichte dieser Begriff ist) wird das Gesicht za einem "gediegenen Bilde“, das sich an die gegebene Gestalt der Sinnenwelt anschliebt, und seinen Träger befähigt die Welt nach Gottes Bilde zu bilden. Immer neue Gesichte zu sehen and sie praktisch zu machen, das ist die Bestimmung der Gelehrten. Sie sind freie Künstler der Zukunft und der Geschichte, besonnene Banmeister der Welt ans dem Volk als dem bewaBtlosen Stoff, sind also die eigentliche Lebenskraft in der Welt, die Triebfeder der Fortsetzung der Schöpfung, das Salz der Erde ${ }^{2}$ ). Und während es für die Masse der Religiösen ein zukünftiges und himmlisches aber mit dem irdischen gar nicht zusammenhängendes Leben gibt, auf das man sich durch Gutestan nur vorbereiten kann, kennt der Gelehrte neine unendlicine Reihe künftiger Welten über Welten, welche insgesamt von der gegenwärtigen ersten nicht der Art nach, sondern nar der Stufenfolge nach nnterschieden, ... and er befindet sich mitten in der Ewigkeit, indem schon hier allgegenwärtig das Übersinnliche ihn nmgibt ${ }^{\mu .8}$ ).

1) NW. III, 53 (Bestinmung des Gelehrten 1811).

2) NW. III, 160 ff.

3) Staatsl. $394 \mathrm{ff}$. 
Deatlicher kann nicht ausgesprochen werden, was die neue Ethik für das Problem der Geschichte als sittlicher Kontinuität bedeatet. Ist das Sittengesetz eine Form, so ist alles Wirkliche bloßer Verwirklichungsfall, alles Materiale bloßes Material. Die Leistungen erbanen nicht eine konkrete Kontinuität als ibre Synthese, sondern die einzige Synthesis, die möglich ist, ist die der reinen Willen za einem transzendenten Reich, das mit der geschichtlich-sozialen Wirklichkeit nichts za tan hat. So der reine Moralismus, so das erste System der Fichteschen Sittenlehre. Erst wenn das Wesen des Sittlichen in die Verwirklichung eines materialbestimmten Bildes gesetzt wird, wenn es also nicht bloB ${ }_{n}$ sittliche

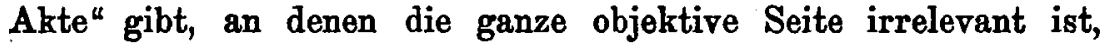
sondern sittliche Leistungen, die als individuelle and konkrete von Wert sind: erst dann gibt es eine Geschichte, deren Sinn der Aufbau einer objektiven geistigen Welt, deren Sinn es ist „Übersinnliches za verflöBen in unser irdisches Tagewerk". 